\title{
TEC behavior over the Mexican region
}

\author{
M.A. Sergeeva ${ }^{1,2, *}$, O.A. Maltseva ${ }^{3}$, J.-A. Gonzalez-Esparza ${ }^{1}$, J.C. Mejia-Ambriz ${ }^{1,2}$, V. De la Luz ${ }^{1,2}$, \\ P. Corona-Romero ${ }^{1,2}$, L.X. Gonzalez ${ }^{1,2}$, V.J. Gatica-Acevedo ${ }^{4}$, E. Romero-Hernandez ${ }^{5}$, \\ M. Rodriguez-Martinez ${ }^{6}$, E. Aguilar-Rodriguez ${ }^{7}$
}

${ }^{1}$ SCiESMEX, LANCE, Instituto de Geofisica, Unidad Michoacan, Universidad Nacional Autonoma de Mexico, Morelia, Mexico

2 CONACYT, Instituto de Geofisica, Unidad Michoacan, Universidad Nacional Autonoma de Mexico, Morelia, Mexico

${ }^{3}$ Institute for Physics, Southern Federal University, Rostov-on-Don, Russia

${ }^{4}$ Instituto Politecnico Nacional, Mexico City, Mexico.

${ }^{5}$ LANCE, Facultad de Ciencias Fisico-Matematicas, Universidad Autonoma de Nuevo Leon, Monterrey, Mexico

${ }^{6}$ Escuela Nacional de Estudios Superiores Unidad Morelia, Universidad Nacional Autonoma de Mexico, Mexico

${ }^{7}$ Instituto de Geofisica, Unidad Michoacan, Universidad Nacional Autonoma de Mexico, Morelia, Mexico

Article history

Received June 13, 2017; accepted January 15, 2018.

Subject classification:

Ionosphere; Space weather.

\begin{abstract}
With the advent of the Navigation Satellites the Total Electron Content (TEC) has become one of the main parameters of the ionosphere. This is the result of a continuous TEC monitoring and rather dense network of GPS receivers. For Mexican region having no ionosondes the use of TEC for ionospheric conditions studies and monitoring has a special value. To study the behaviour of TEC and for its applied aspects two types of source-files are used worldwide: IONEX (global maps) and RINEX (local data) depending on the task solved. Magnetometer and satellite data from CHAMP and DMSP were involved in the analysis. First, benefits and limitations of TEC derived from both types of files are discussed in regard to the estimation of the ionosphere state in the Mexican region. Second, using both methods the specific features of diurnal, seasonal and annual patterns in TEC behaviour over Mexico were revealed, among which are the shift of the diurnal maximum to $14 \mathrm{LT}$, dependence on solar activity, high probability of night-time enhancements, presence of annual and winter anomalies. Third, it was revealed that the positive short-lived TEC enhancements are characteristic for Mexican region. They may occur even under quiet conditions. The answer is given what part of the ionosphere is responsible for TEC change during these positive disturbances. The results for Mexico were compared to the neighboring regions and South-East zone.
\end{abstract}

\section{Introduction}

In October of 2014 the Mexican Space Weather Service (SCiESMEX) was established with aims to study, analyze and forecast Space Weather (SW) impacts over the Mexican region (geographic latitudes $14^{\circ}-32^{\circ} \mathrm{N}$, geomagnetic latitudes $\left.23^{\circ}-38^{\circ} \mathrm{N}\right)$. There are no ionosondes in Mexico, so for the ionosphere state estimation SCiESMEX relies on TEC derived from Global Positioning System (GPS) data. Since September 2015 Total Electron Content (TEC) variations over Mexico are being continuously monitored [GonzalezEsparza et al. 2017]. The continuous measurements of TEC were not analyzed before, that is why the climatological features of ionosphere in the region remain not sufficiently described.

The SW effects are most prominent during geomagnetic disturbances [Blagoveshchensky 2011] which in turn, cause disturbances in the ionosphere. The ionosphere disturbance manifestations over Mexico were reported in a number of works [Rodríguez-Martínez et al. 2014, Lopez-Montes et al. 2015, Carillo-Vargas et al. 2011, Carillo-Vargas et al. 2016]. Some individual storm events and their effects were discussed in works [Ho et al. 1998, Cipagauta-Lara and Durand-Manterola 2010]. The issue of flare associated TEC variation over Mexico was addressed in Lopez-Montes et al. [2012]. Still ionosphere studies in the American sector within the latitudes $20^{\circ} \mathrm{N}-40^{\circ} \mathrm{N}$ are limited.

It is impossible to estimate the intensity of distur- 
bance in the ionosphere without knowing its expected quiet reference state. However, there is no description or climatological study of regular ionosphere behavior over Mexico. In the present work we try to partly fill this gap and to describe diurnal, monthly, seasonal and annual trends in the ionosphere. Another task is to reveal advantages and limitations of using TEC derived from data of local GNSS receiver stations versus those obtained from global ionospheric maps. The third task is to reveal specific features of TEC behavior during positive disturbances for the periods of high and low solar activity. More specifically the answers to two questions are pursued: (a) whether the positive TEC enhancements are characteristic for Mexican region; and (b) what part of the ionosphere is responsible for the TEC change during disturbances. New results are summarized in Conclusions.

The paper is organized as follows. Section 2 introduces the data analyzed, in particular, Section 2.1 describes four types of data we used, Section 2.2 presents the results of comparison of TEC calculated using two methods under quiet and disturbed conditions. Section 3 concerns results of long and shortterm observations. In particular, Sections 3.1 and 3.3 discuss regular variations in TEC over Mexico and Sections 3.2 and 3.4 describe some specific features. Section 3.5 is focused on TEC specifically during the positive disturbances within the periods of high (Section 3.5.1) and low (Section 3.5.2) solar activity. Final remarks are given in Conclusions.

\section{Data used for the analysis}

\subsection{Types of data used for the present study}

2.1.1. GIM $v$ TEC: In this study values of vertical total electron content (vTEC) are reconstructed using the data extracted from GPS signals. First, vTEC data provided by the global ionospheric maps (GIM) are produced by four Analysis Centers of the International GPS Service for Geodynamics: (a) the Center for Orbit Determination in Europe (CODE), Astronomical Institute, University of Berne, Switzerland [Schaer et al. 1995], (b) Technical University of Catalonia (UPC), Barcelona, Spain [Hernandez-Pajares et al. 1997], (c) European Space Operations Center of European Space Agency (ESA), Darmstadt, Germany [Sardon et al. 1994, Jakowski et al. 1996], (d) the Jet Propulsion Laboratory (JPL), California Institute of Technology, U.S.A. [Mannucci et al. 1998]. Then these vTEC maps independently computed by different centers are ranked and combined according to corresponding weight by the International GNSS Service
(IGS) to produce the IGS global vTEC maps [HernandezPajares et al. 2009]. JPL and IGS maps were used in this study. GIM vTEC provide the opportunity to validate local maps that are produced by various national institutions based on different algorithms and assumptions. The GIM vTEC values were obtained from IONEX-files, freely available by following the link $\mathrm{ftp}$ // cddis.gsfc.nasa.gov/pub/gps/products/ionex. The spatial resolution is $5^{\circ}$ longitude and $2.5^{\circ}$ latitude worldwide.

2.1.2. TayAbsTEC vTEC: Data extracted from RINEX-files of local GPS receivers was processed by "tec-suite" software to calculate slant TEC (sTEC) values. Then vTEC values were obtained from "TayAbsTEC" software designed by Institute of Solar-Terrestrial Physics, Siberian Branch, Russian Academy of Sciences, in the framework of the new method [Yasyukevich et al. 2015(b), Mylnikova and Yasyukevich 2016]. This method accounts for the receiver coordinates when calculating vTEC. It is known, that the mapping function influences a lot on the accuracy of the absolute vTEC estimation [Schaer et al. 1998]. After analyzing mapping functions for a number of observation points using the stations of IGS network and simulations based on IRI-2012 the authors [Mylnikova and Yasyukevich 2016, Yasyukevich et al. 2015a, Yasyukevich et al. 2015b] showed that the changes of sTEC occurred with different velocities in various regions of the Earth due to different angles of the satellite passage at different latitudes. They introduced experimentally-determined correction factors $\alpha$ to convert sTEC to vTEC. Namely, $\alpha=\sim 0.94$ for the Arctic region and $\alpha=\sim 0.87$ for the equatorial latitudes. We use the correction factor $\alpha=0.90$ for Mexican latitudes. Another particular feature of the method is the use of Taylor series in the data processing. As a rule, the spherical function expansion is used in the literature [Mannucci et al. 1998, Schaer et al. 1998]. The function used to model vTEC in our case is equivalent to a Taylor expansion of second order [Yasyukevich et al. 2015 (a)], meaning an estimation of the linear and quadratic derivatives in space and time. More details on the method can be found in the literature cited above. Hereafter, TEC means vertical TEC unless otherwise specified.

The database for our calculations consists of RINEX-files of local receivers belonging to the following networks: 1) the Mexican Servicio Sismológico Nacional ("SSN"), 2) Trans-boundary, Land and Atmosphere Long-term Observational and Collaborative Network ("TLALOCNet") 3) "SSN-TLALOCNet" 


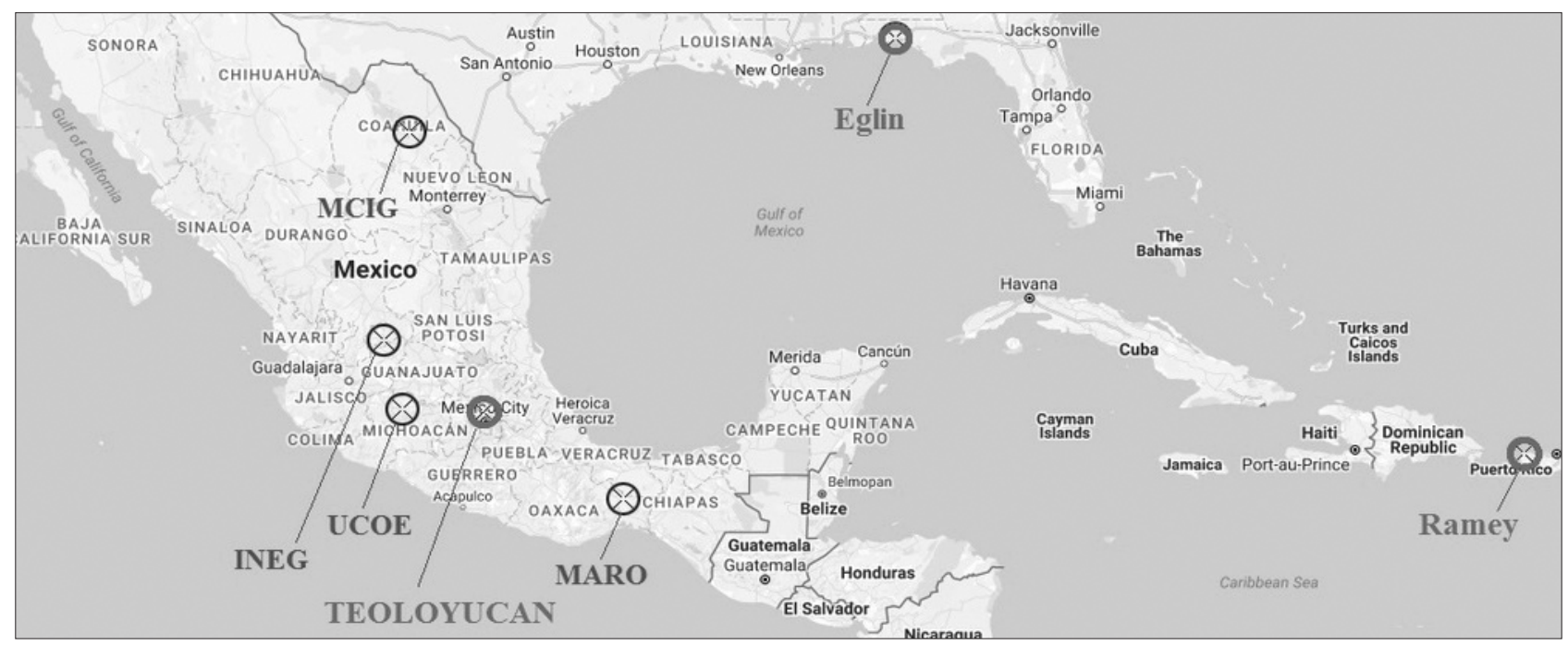

Figure 1. Map of the considered stations.

and 4) the network of the permanent GPS stations "IGEF-UNAM". One of the base stations for our analysis (UCOE) is installed in the site of the Mexican Array Radio Telescope (http:/ / www.mexart.unam.mx/). Figure 1 illustrates the locations of some GPS receivers whose data was used in the present analysis. Table 1 represents the coordinates of different stations.

2.1.3. foF2 data: The third type of data used is the critical frequencies of F2-layer (foF2) from Eglin Air

\begin{tabular}{|c|c|c|c|c|c|c|}
\hline $\mathbf{N}^{\circ}$ & Station code & Description & $\begin{array}{l}\text { Geographic } \\
\text { latitude, } \mathrm{N}\end{array}$ & $\begin{array}{l}\text { Geographic } \\
\text { longitude, E }\end{array}$ & $\begin{array}{l}\text { Geomagnetic } \\
\text { latitude, } \mathrm{N}\end{array}$ & $\begin{array}{l}\text { Geomagnetc } \\
\text { longitude, E }\end{array}$ \\
\hline 1 & INEG & GPS receiver station (Mexico) & 21.85 & -102.28 & 30.06 & -32.08 \\
\hline 2 & UCOE & GPS receiver station (Mexico) & 19.8 & -101.68 & 28.06 & -31.22 \\
\hline 3 & MCIG & GPS receiver station (Mexico) & 27.877 & -101.484 & 36.07 & -31.91 \\
\hline 4 & MARO & $\begin{array}{c}\text { GPS receiver } \\
\text { station (Mexico) }\end{array}$ & 17.091 & -94.884 & 25.9 & -24.75 \\
\hline 5 & Mexico station & $\begin{array}{l}\text { Mexico City coordinates used to } \\
\text { extract data from GIM }\end{array}$ & 19.3 & -99.1 & 27.78 & -28.42 \\
\hline 6 & Millstone Hill & $\begin{array}{l}\text { GPS receiver station (USA) used } \\
\text { in work [Sojka et al. 2012] }\end{array}$ & 42.6 & -71.5 & 52.1 & -1.35 \\
\hline 7 & Chilton & $\begin{array}{c}\text { GPS receiver station (UK) used in } \\
\text { work [Cander and } \\
\text { Ciraolo 2009] }\end{array}$ & 51.6 & 358.7 & 53.53 & 83.69 \\
\hline 8 & EG931 & Eglin (USA) ionosonde station & 30.5 & -86.5 & 39.71 & -15.61 \\
\hline 9 & PRJ18 & $\begin{array}{c}\text { Ramey (Puerto Rico) ionosonde } \\
\text { station }\end{array}$ & 18.5 & -67.1 & 28.03 & 5.94 \\
\hline 10 & TEO & $\begin{array}{l}\text { Magnetic observatory of TEO- } \\
\text { LOYUCAN (Mexico) }\end{array}$ & 19.733 & -99.183 & 28.21 & -28.55 \\
\hline
\end{tabular}

Table 1. Coordinates of GPS receiver stations, ionosonde stations and magnetometer used in the study. 
Force Base (AFB) (USA) and Ramey (Puerto Rico). The locations of the ionosondes are illustrated in Figure 1. The foF2 data was obtained from the SPIDR data base http://spidr.ngdc.noaa.gov/spidr/index.jsp.

2.1.4. Plasma frequency data: Another type of data is the plasma frequency values from the low-altitude satellites CHAMP (http:/ isdc.gfz-potsdam.de) and DMSP (http: / / cindispace.utdallas.edu / DMSP / dmsp_ data_at_utdallas.html). The altitudes of orbits (h) in November 2001 were $\mathrm{h}($ CHAMP $)=\sim 440 \mathrm{~km}$ and $\mathrm{h}($ DMSP $)=\sim 840 \mathrm{~km}$. The altitude of CHAMP orbit from January 2006 to November 2007 was near 345-350 km.

2.1.5. Ground Magnetic Data and Indices: Dst-index and $\mathrm{Kp}$-index values were used. These indices are indicators of global SW effects. In addition, to understand the local magnetic field change, the data from Teoloyucan magnetic observatory located in the center of Mexico was used (Figure 1).

\subsection{GIM and local TEC data in Mexico}

TEC values can differ a lot depending on the method of their calculation [Arikan et al. 2003, Çepni et al. 2013]. To monitor the ionospheric state over Mexico two options were considered: GIM TEC values and TEC values extracted from GPS signals received by stations of local networks and then processed with TayAbsTEC software. The following parameters were calculated in both cases: absolute TEC values, median TEC values for the 27-prior days to the day of observation, ionospheric weather Windex corresponding to the logarithmic deviation from the median (DTEC) [Gulyaeva et al. 2013] and TEC deviation ( $\delta T E C)$ from its 27 -day median on a percentage base. We compared benefits and limitations of global and local data and their corresponding methods of calculation for five years of data between 2011 and 2015 and the first half of 2016 (during quiet periods and geomagnetic storms of different intensity). Typical example of comparison is illustrated in Figure 2 (panel a) for coordinates of UCOE station. GIM TEC data used here was the IGS TEC. Data of local MCIG station was added to verify the tendency in TEC change. Magnetometer data (panel b) and ionospheric weather W-index on the base of GIM DTEC curve (panel c) are shown to illustrate the development of geomagnetic and ionospheric disturbances respectively. In this Section we only compare results obtained from two methods of TEC calibration. The analysis of the ionosphere variations is given in Section 3.

The comparison of the results of GIM and local
TEC over Mexico under quiet conditions showed a good agreement between two types of data. The nondisturbed day September 6th, 2015 (Dst $=-28 \mathrm{nT}$, $\mathrm{Kp}=4$ ) serves as an example (Figure 2): the curves representing the results of two methods of TEC calculation for station UCOE are similar. As an example of disturbed period, we consider the moderate storm on September 9-10, 2015 (Dst= -97 nT, Kp=6) developed on the background of the preceding weaker disturbance. In general, the forms of both curves of TEC (by GIM and by TayAbsTEC) for UCOE station are similar: 1) the moderate TEC disturbance on September 7-8, 2015 (UT) probably caused by H-component decrease between 16 UT September $7^{\text {th }}$ and 02 UT September $8^{\text {th }}$ (main phase of the storm), 2) still high TEC values during the recovery in the H-component (the following 18 hours) and 3) negative TEC disturbance on September 9-10, 2015 (UT) caused by another perturbation in the magnetic field that developed at already disturbed background. The amplitude of TEC for MCIG is lower than for UCOE because of the difference in the latitudes of these receivers (Table 1, Figure 1). The higher the latitude the less is the peak-to-peak amplitude of TEC [Afraimovich and Perevalova 2006]. However, the general course of TEC is similar: the increase on September 7-8 and significant decrease on September $9^{\text {th }}$ comparing with TEC on the day prior to the disturbance.

From the example in Figure 2 and other analyses (not shown), we find that the algorithm for the calculation of local TEC values provides a reasonable result. Further, global maps reflect the ionosphere state over the region rather well. Both local and global methods of TEC estimation have their benefits and limitations. First, GIM TEC data is available from the Internet with a delay (from three days or more depending on the laboratory). In contrast, the local TEC data can be used for quasi real-time monitoring. Second, since there is only one IGS GPS receiver station in Mexico, INEG station (see Table 1), the spatial interpolation in TEC calculation plays the major role for this region. Thus, this should be taken into account and GIM should be used with reserve in this region. At the same time, the network of local stations is rather dense. Among other limitations of GIM is the temporal resolution of one or two hours. The temporal resolution for TEC by local RINEX-data is limited by the program used to calculate the parameter and in our case it is three minutes. Hence, the local TEC data provides more detailed information about the ionosphere state than GIM. The ionospheric variations of 

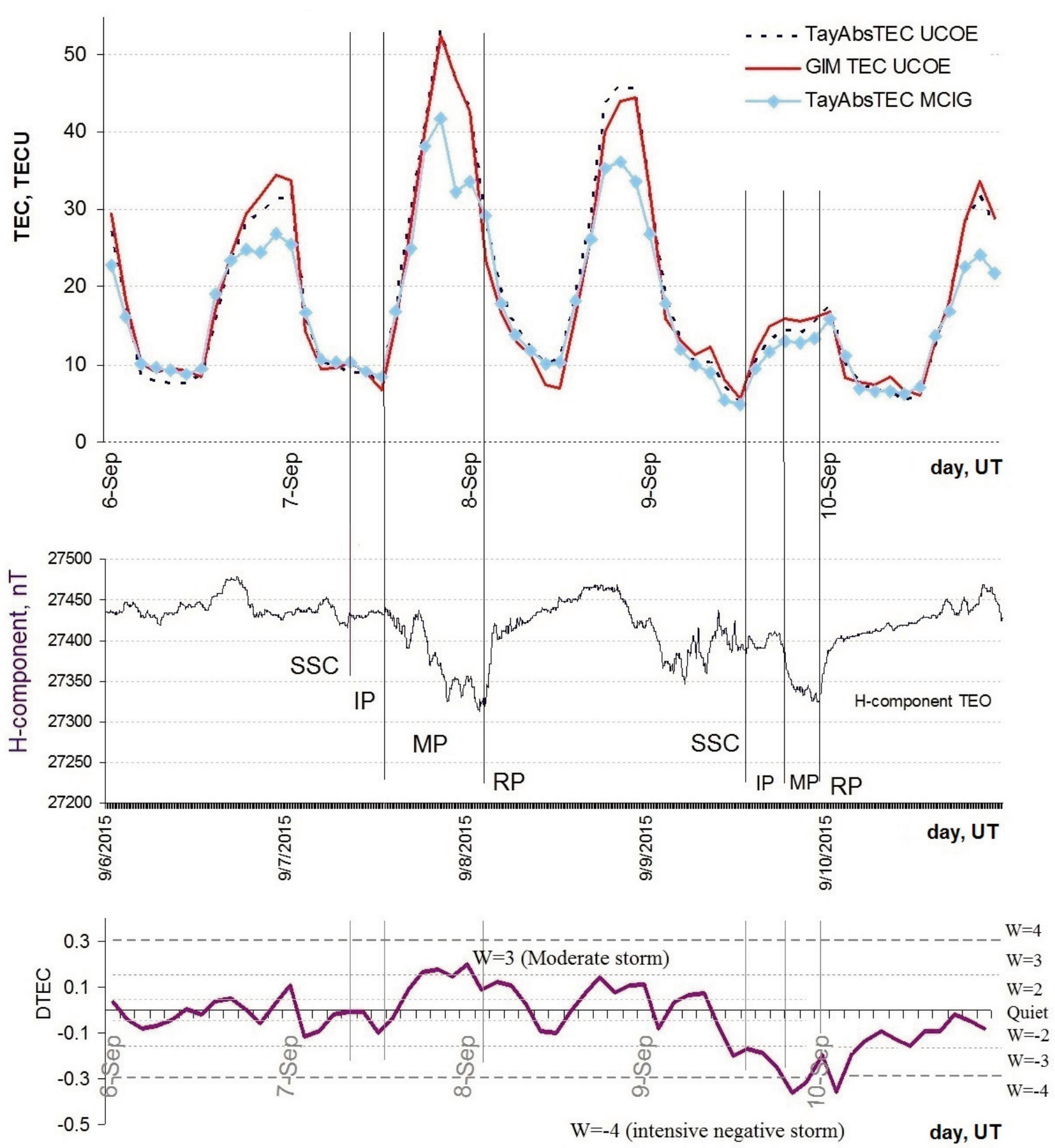

Figure 2. TEC by GIM for UCOE station and TEC by TayAbsTEC for UCOE and MCIG stations during September 6-10, 2015 (panel a). Variations of H-component of the magnetic field (panel b). DTEC and ionospheric weather W-index (panel c). IP, MP and RP are the initial, main and recovery phase of the storm respectively. SSC is Sudden Storm Commencement.

small scale can be observed only with local data. It was also found that in the majority of cases the global data manifests less intensity of ionospheric response than local TEC. This fact is important for making estimates of the ionosphere state change. On the other hand, local data may be not always available: the lack of continuous measurements is not uncommon for the past periods. In contrast, the GIM TEC is the data being collected continuously from 1998 [HernandezPajares at al. 2009]. This is its advantage: GIM helps to estimate the character of TEC change for the past periods or in the case of an occasional gap in local data in present.

To conclude, both TEC methods discussed in this Section can be used to estimate the ionosphere state over Mexico. This allows us to estimate adequately the data of earlier periods and perform the current detailed diagnostics of TEC over Mexico. The limitations for GIM use are delayed availability, low temporal resolution and lack of IGS stations in the Mexican region. 


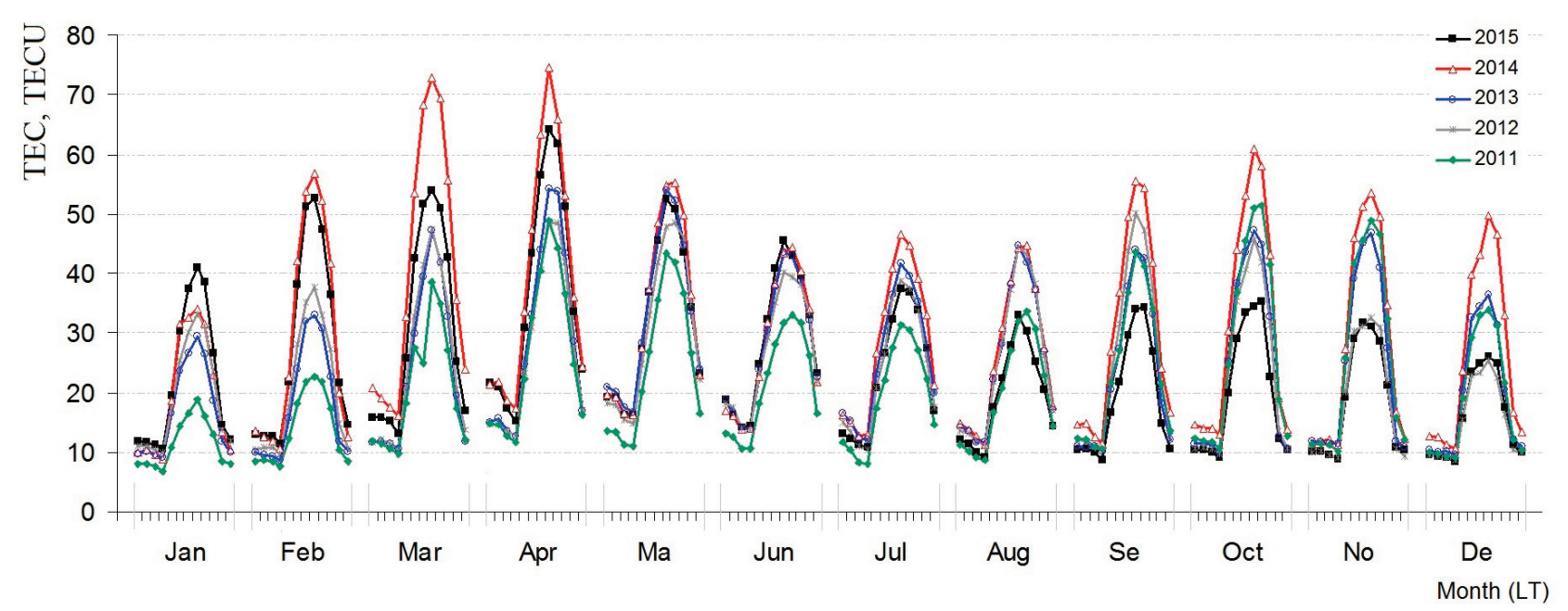

Figure 3. Monthly median daily TEC values for each month of the year during five years for INEG station in Mexico.

\begin{tabular}{lccccccccccccc}
\hline Local Time (LT) & 0 & 2 & 4 & 6 & 8 & 10 & 12 & 14 & 16 & 18 & 20 & 22 \\
& & & & & & & & & & & \\
& & & & & & & & & & & & & \\
$\rho($ F10.7-TEC) & 0.30 & 0.29 & 0.35 & 0.40 & 0.69 & 0.78 & 0.66 & 0.60 & 0.55 & 0.41 & 0.22 & 0.27 \\
\hline
\end{tabular}

Table 2. Correlation coefficients between TEC and F10.7 values at different local hours of the day.

\section{Discussion of regular patterns and peculiarities of TEC over Mexico}

\subsection{Annual variations}

To study the character of annual, daily and seasonal TEC variations data during a five-year period between 2011 and 2015 was analyzed. According to data by OMNI Database, the radio emission from the Sun at a wavelength of $10.7 \mathrm{~cm}$ (F10.7 cm solar flux) has changed within this period as follows: 75 - 195 s.f.u. during 2011 , 85 - 185 s.f.u. during 2012,90 - 175 s.f.u. during 2013, 90 - 260 s.f.u. during 2014 and 80 - 170 s.f.u. during 2015 with the only exception of high value (255 s.f.u.) on June 22, 2015. The amplitudes of Mexican TEC lay approximately within the limits of 20-55 TECU in 2011, 25-50 TECU in 2012, 30-60 TECU in 2013, 45-75 TECU in 2014 (Figure 3). In 2014 the amplitudes were the highest within the considered five-year period. This fact is easily explained by the maximum of solar activity of cycle 24 in 2014. In 2015 the peak-to-peak amplitude is lower than in 2014 but still high as TEC values lay within 30-65 TECU. It is seen that TEC increases with growth of solar activity. Table 2 shows the correlation coefficients $(\rho)$ between TEC and F10.7 values for different local hours of a day during the period $2011-2015$. For the whole five-year period $\rho=0.6$ for TEC at 14 LT (diurnal maximum, See Section 3.3) and maximal correlation $\rho=0.8$ was for TEC at $10 \mathrm{LT}$.

In general, the annual pattern of TEC trend in Mexico is as follows: (1) TEC values are high during April and usually October. However, the highest autumn values in 2011 were observed in November and in 2012 - in September. (2) The lowest TEC values were usually observed during December-January and July. Here, when saying the highest and the lowest TEC values we refer to daily maximum values. (3) The "annual anomaly" that is the presence of two minima in TEC within a year is clearly seen from Figure 3 and further confirmed by Figures 5 and 6 . The result of issue (3) sometimes is called "semi-annual anomaly" which implies that TEC values are higher near equinoxes than near solstices. However, in our case, the periods of highest and lowest TEC do not exactly coincide with June/December and March/September, but are shifted in time. This shift is not stable and depends on the year. Thus, it would be more correct to refer these features to the part of the annual trend [Azpilicueta et al. 2012].

To sum up, two "maxima" and two "minima" were found in the annual TEC trend over Mexico. During the years of higher solar activity TEC has higher amplitudes as well.

\subsection{Specific features in annual TEC behaviour}

There are few studies of TEC for low-latitude regions such as Mexico, as the number of stations in lowlatitudes is less than at mid-latitudes. That is why it is of interest to compare Mexico to other low-latitude zones. One of them, the South-East zone is being intensively studied. In work [Liu et al. 2014] TEC monthly medians and $\mathrm{NmF} 2$ data were compared over the area of China ac- 

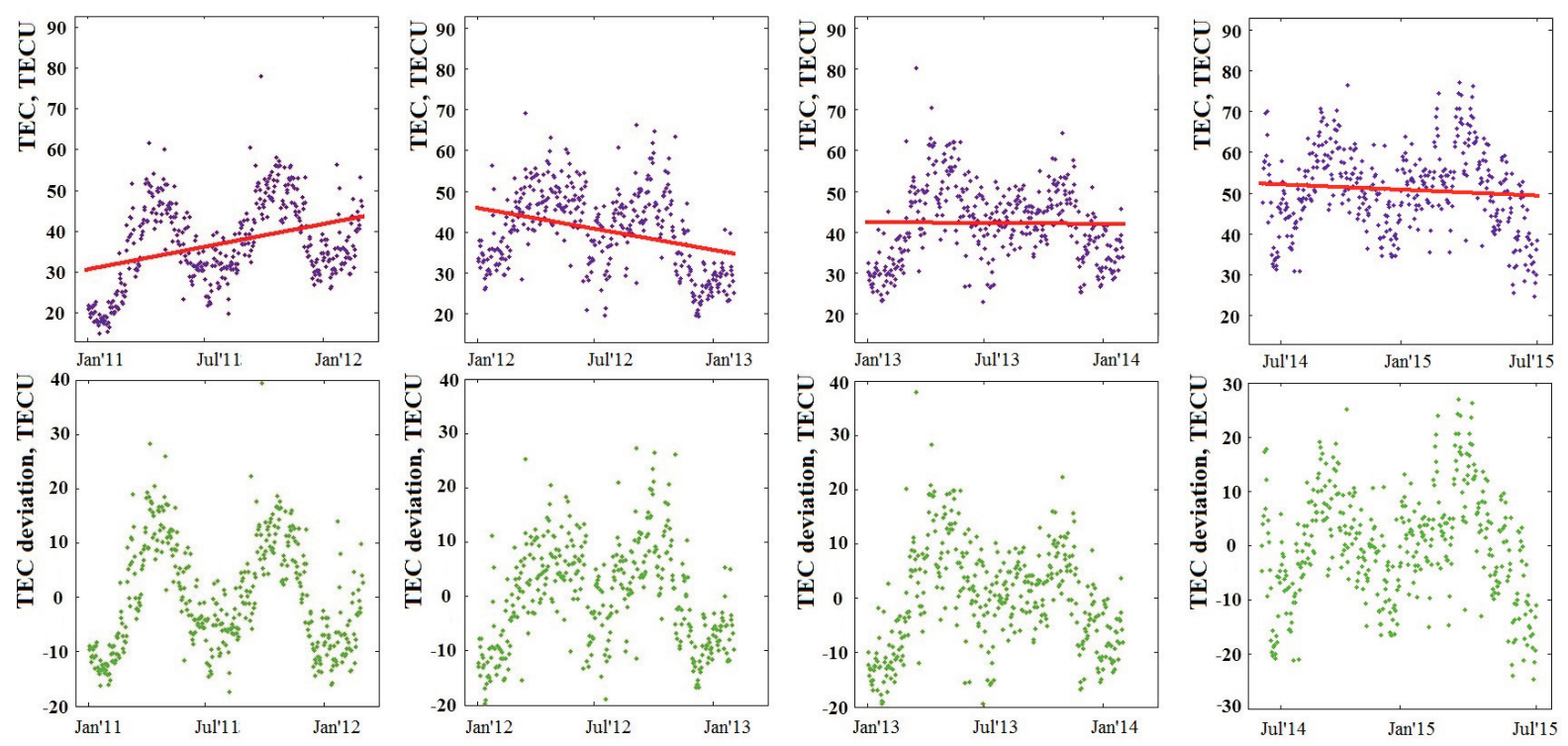

Figure 4. TEC values at $14 \mathrm{LT}$ and cycle effect represented by trend lines for INEG station (upper panels). TEC deviation from the trend (lower panels).

cording to data from 34 GPS stations and 10 ionosondes in 2004. In the case of station Guangzhou (geographic coordinates $23.1^{\circ} \mathrm{N}, 113.4^{\circ} \mathrm{E}$ ) the peculiarities of diurnal and seasonal trends were revealed: (1) the maximum values of TEC and NmF2 took place after noon, notably that $\mathrm{NmF} 2$ maximum occurred one-two hours later than the moment of TEC maximum; (2) the seasonal dependence was characterized by the presence of the maximums in March and October as well as by the presence of "winter anomaly" which means that the winter $\mathrm{NmF} 2$ values are comparable or higher than summer values. The same anomaly in TEC values was not revealed. Though this station is the most southward in the study [Liu et al. 2014], the similar results were obtained for other stations. It was of interest to check the presence of "winter anomaly" for the Mexican region.

For this purpose the highest and the lowest median values of maximum diurnal TEC between 2011 and 2015 were analyzed. For comparison between values of different years the solar activity effect was filtered. As it was mentioned in Section 3.1, the growing solar activity causes the growth of TEC amplitudes and, consequently, it can be the dominant cause of winter values being comparable/higher than values of the preceding summer (increasing solar radiation in the course of the cycle). The opposite effect can occur during the decrease of solar activity. This effect is usually filtered to check only seasonal variation of TEC [Azpilicueta et al. 2012]. Thus, the comparison of summer and winter values is made for various periods with the approximate duration of one year. It can be considered that within these short periods the smoothed monthly value of F10.7 had just increasing or just decreasing tendency and, therefore, solar ac- tivity is represented by linear trend for each period. Figure 4 shows daily maximum TEC values (at $14 \mathrm{LT}$ ) plotted versus time for INEG station for four short periods between 2011 and 2015. Each upper panel shows absolute TEC values during the period of approximately one year (blue points) and the cycle effect represented by a trend line (red lines). Lower panels illustrate deviation of TEC values (green points) from the trend lines. Each lower panel corresponds in time interval to the panel above it. It is seen that winter values are comparable to summer values that means the "winter anomaly" presence.

To sum up, our results confirm that the ionosphere has common features at different low-latitude zones of the northern hemisphere. For example, there is a shift to the afternoon hours in the maximum TEC values. At the same time there are different features in TEC. For example, the "winter anomaly" by TEC was revealed in Mexico in contrast to East-South zone. Nonetheless, it is not known if it exists in the NmF2 values $\left(\mathrm{foF} 2=897^{\star} \mathrm{SQRT}(\mathrm{NmF} 2)\right.$ ) as currently there are no ionosonde foF 2 measurements in Mexico. Here, we briefly notice that there is a presence of a "winter anomaly" in Eglin region (located higher than Mexico) revealed when analyzing TEC (GIM) and foF2 data.

\subsection{Diurnal and seasonal variations}

The analysis of diurnal variations of TEC during different years showed that as usual the main diurnal maximum was observed near 14 hours local time (LT) or 20 hours universal time (UT), which confirms the existing understanding of TEC diurnal behaviour for these latitudes [Afraimovich and Perevalova 2006]. Figure 5 provides the example of this trend for 2015. 

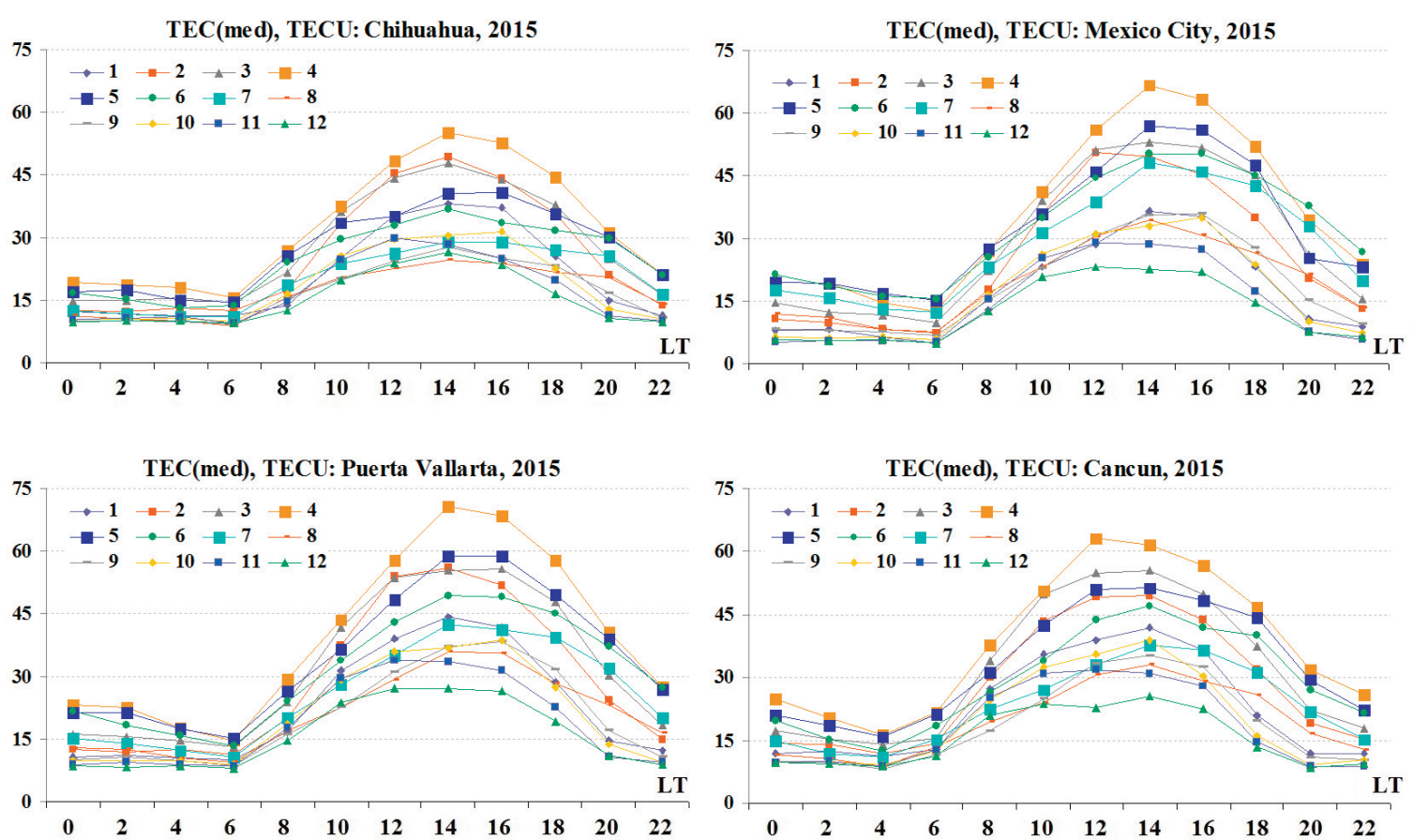

Figure 5. Diurnal TEC trend for four locations in Mexico (monthly median values) in 2015. Months of the year are labeled with numbers.
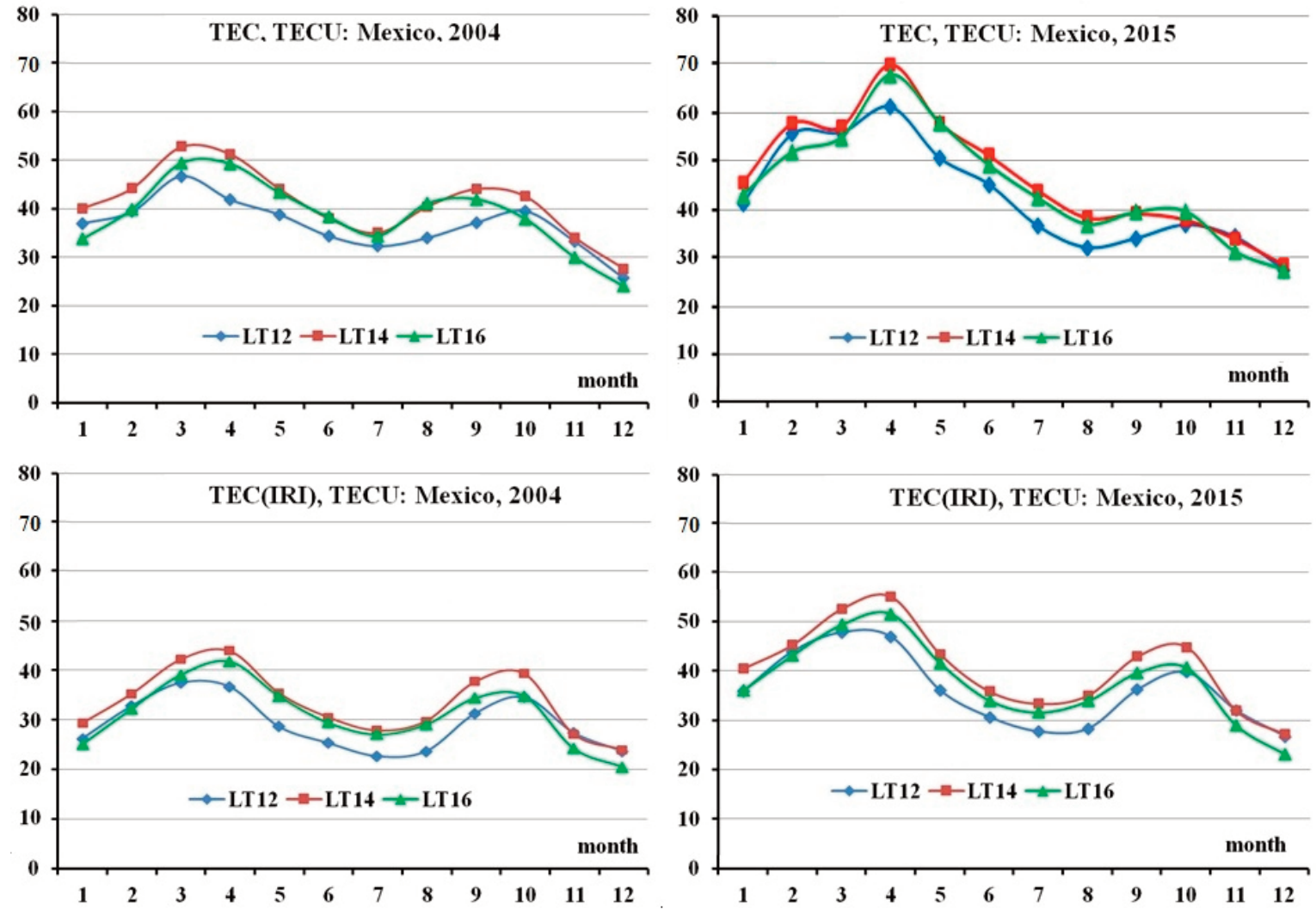

Figure 6. Seasonal trend in TEC values for Mexico station $\left(19.3^{\circ} \mathrm{N}, 99.1^{\circ} \mathrm{W}\right)$ in 2004 and 2015: experimental (upper panels) and modeled by IRI results (lower panels).

Monthly median values are shown for four locations at different geographical latitudes and longitudes in Mexico labeled with the name of the place as follows: Mexico City (lat $19.3^{\circ} \mathrm{N}$, lon $99.1^{\circ} \mathrm{W}$ ), Cancun (lat $21^{\circ} \mathrm{N}$, lon $87^{\circ} \mathrm{W}$ ), Puerto Vallarta (lat $20.7^{\circ} \mathrm{N}$, lon $105.2^{\circ} \mathrm{W}$ ), Chihuahua (lat $29^{\circ} \mathrm{N}$, lon $105.2^{\circ} \mathrm{W}$ ). The diurnal maximum is manifested at $14 \mathrm{LT}$ in all four locations with the following exceptions: (a) at 12 LT - in November for all four 
locations, in December and February in Mexico City, in April in Cancun; and (b) at 16 LT - during September-October in Mexico City and Puerto Vallarta, in October and May in Chihuahua. Nevertheless, the general tendency is the diurnal TEC maximum being at 14 LT over the Mexican territory.

Figure 6 (upper panels) confirms this fact. Curves of TEC monthly median at three particular local hours $(12,14,16 \mathrm{LT})$ are plotted for every month of 2004 and 2015. Both years are found on the descending half of solar cycles 23 and 24 with F10.7 varying within $(80-170)$ s.f.u. in 2015 and (80-180) s.f.u. in 2004. The maximum in the diurnal TEC trend in 2015 is observed at 14 LT repeating the tendency of the previous solar cycle in 2004. The difference is that the maxima in the seasonal TEC trend in 2015 were pronounced in April and October in contrast to 2004 when they fell on March and September. In addition, the autumn maximum in 2015 is much less obvious than in 2004.

The results were compared to TEC obtained from International Reference Model 2012 (IRI) [Bilitza et al. 2012] (Figure 6, lower panels). IRI shows the diurnal maximum always at $14 \mathrm{LT}$ in contrast to experimental TEC with possible maxima at 12 or 16 LT in some cases. The general seasonal tendency of experimental and IRI curves are similar in 2004. However, in 2015 the seasonal pattern is less expected: the climatology model predicted a well-pronounced autumn maximum that was only slightly observed with the experiment. To add, a higher difference was expected between TEC values at three local hours than the experiment showed. Further, for both years TEC values were rather underestimated: about 10 TECU in 2004 and about 15 TECU in 2015. For some applications the absolute TEC value plays an important role, for instance for estimates of GPS positioning error based on TEC or some ionosphere corrections in satellite applications. Thus, the difference in 10-15 TECU seems to be significant.

To sum up, the comparison of the diurnal and seasonal TEC variations based on experimental data of two types and TEC by the climatology model has shown that the diurnal maximum was observed at $14 \mathrm{LT}$ throughout Mexico during all four seasons. The expected seasonal patterns may not fully coincide with observations.

\subsection{Specific features of diurnal TEC behaviour}

The analysis of TEC over Mexico shows that the diurnal trend in the majority of cases manifests the second TEC maximum at night hours. The curve for MCIG station in Figure 2 (panel a) may be an example. The works [Yakovets et al. 2014, Perna et al. 2014, Kutiev et al. 2006, Unnikrishnan et al.
2002] showed that the night-time enhancements in TEC can be a result of downward plasma flux, rise of the maximum F2-layer height (hmF2) due to the equatorward thermospheric winds or a result of large-scale travelling ionospheric disturbance formations. The last is not our case as we observe this effect continuously through almost a whole year. According to Yakovets et al. [2014], we suppose that the $\mathrm{hmF} 2$ growth may be the cause.

Figure 7 provides the example of night-time enhancements at UCOE and MARO stations located at different latitudes of Mexico for two days in January 2015 with different geomagnetic background. January $7^{\text {th }}$ was characterized with Dst $=-99 \mathrm{nT}$ and variation of the $\mathrm{H}$-component of the magnetic field within $100 \mathrm{nT}$. The ionospheric disturbance on January $8^{\text {th }}$ was provoked by the geomagnetic disturbance the day before, therefore, the values for January $7^{\text {th }}$ are given (panel c). January $17^{\text {th }}$ was characterized with Dst $=-18 \mathrm{nT}$ and $\mathrm{H}$-component variation within $40 \mathrm{nT}$ (panel d). The enhancements in TEC values are clearly seen within 03-09 UT January $8^{\text {th }}$ with the maximum at 04-05 UT (panel a) and within 02-09 UT January $17^{\text {th }}$ with the maximum at 05-06 UT (panel b). In general, sometimes the effect is more pronounced under quiet conditions and sometimes - during ionospheric disturbances over Mexico. The duration of enhancements varies and their maximum may be shifted to morning hours (LT). The probability of night-time TEC enhancements in Mexico is very high (up to $97 \%$ of days of observation during a month). For example, Table 3 illustrates the general picture during three years according to the data of UCOE station. The effect depends on the month and mostly is less pronounced between June and July.

\begin{tabular}{lcccc}
\hline Season & Month & $\mathbf{2 0 1 5}$ & $\mathbf{2 0 1 6}$ & $\mathbf{2 0 1 7}$ \\
\hline \multirow{2}{*}{ Winter } & Jan & 42 & 74 & 93 \\
& Feb & 46 & 69 & 89 \\
\hline \multirow{2}{*}{ Spring } & Mar & 55 & 87 & 58 \\
& Apr & 67 & 63 & 63 \\
& May & 61 & 52 & 65 \\
\hline \multirow{3}{*}{ Summer } & Jun & 47 & 43 & 20 \\
& Jul & 48 & 13 & 32 \\
& Aug & 61 & 55 & 58 \\
\multirow{2}{*}{ Autumn } & Sep & 47 & 70 & 70 \\
& Oct & 52 & 87 & 97 \\
Winter & Nov & 37 & 97 & No data \\
\hline \multirow{2}{*}{ Avaraged over the year } & Dec & 74 & 93 & No data \\
\hline
\end{tabular}

Table 3. The percentage of days with observed night-time TEC enhancements at UCOE station during the period 2015-2017. 


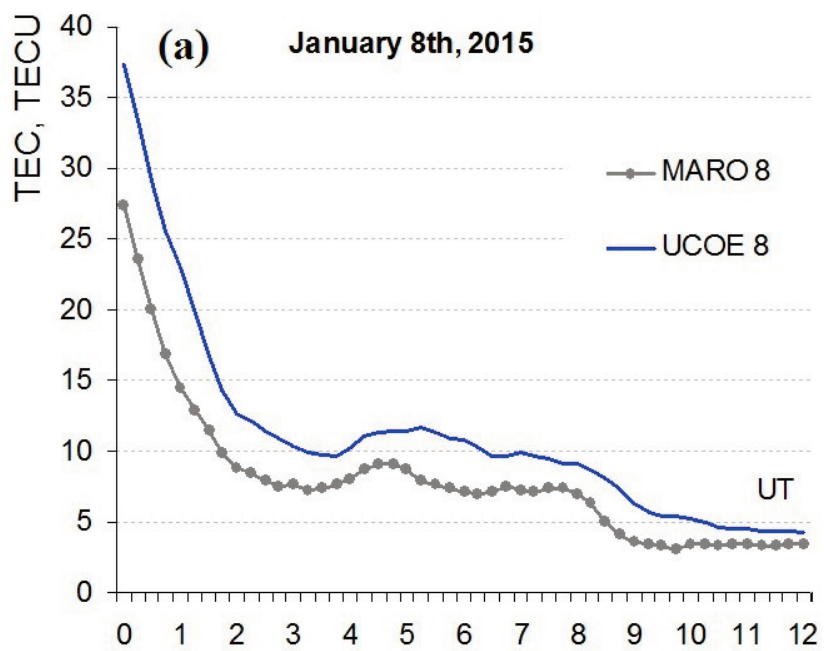

(c)

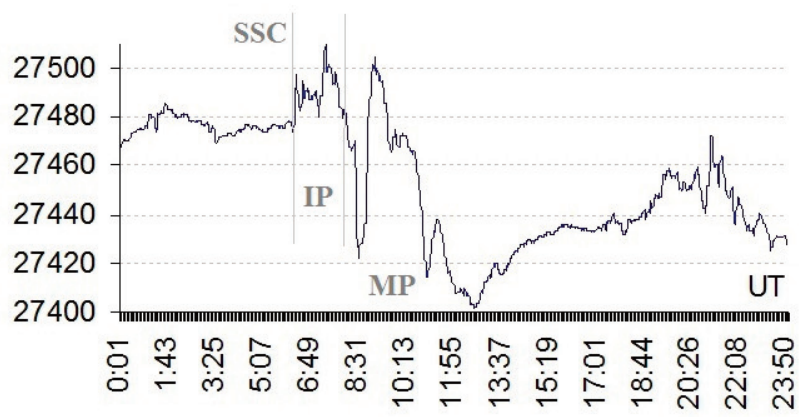

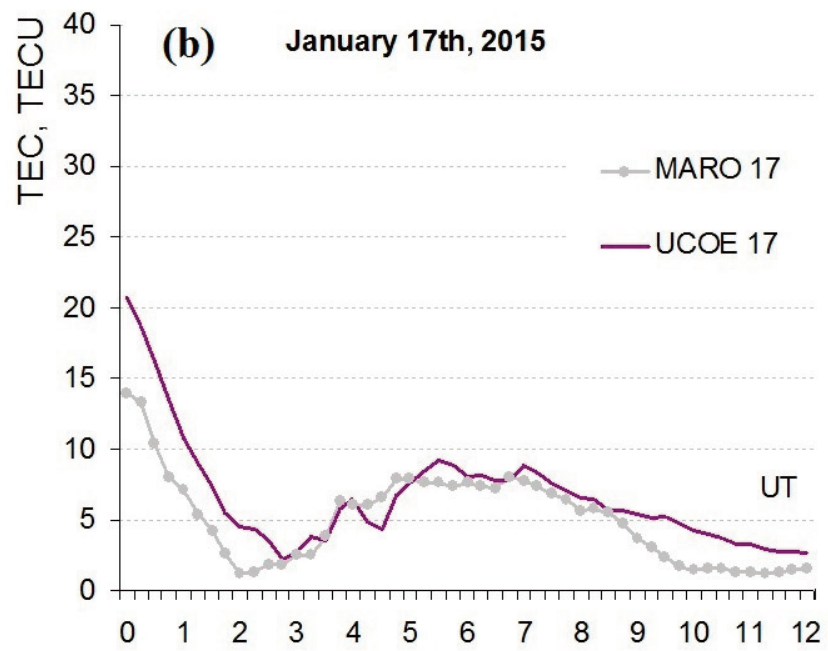

(d) TEO H-component

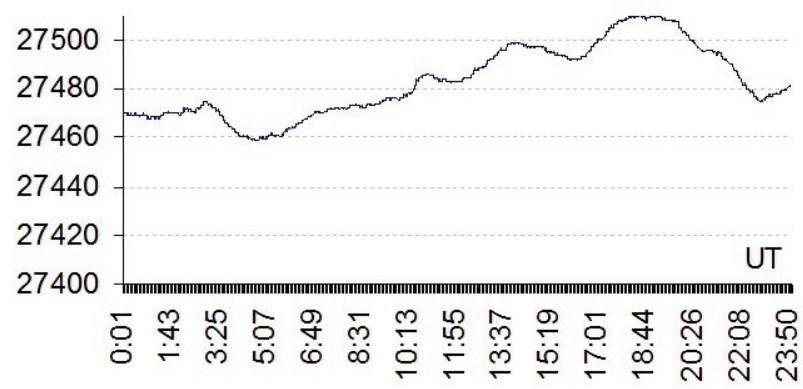

Figure 7. TEC enhancements at night hours on January 8, 2015 (panel a) and January 17, 2015 (panel b) and variations of the H-component of the magnetic field during the whole day of January 7, 2015 (panel c) and January 17, 2015 (panel d).

Another characteristic feature of the diurnal trend is the presence of two peaks within the hours of daily maximum values (M-shape peak). The curve for MCIG station in Figure 2 (panel a) may serve as an example of this phenomenon: M-shape peak occurred on September 6th, 2015 during rather quiet ionospheric conditions (Figure 2. panel c) and on September $7^{\text {th }}$ and $9^{\text {th }}, 2015$ - during ionospheric disturbances. One peak of two in M-shape may be higher/lower than another (Figure 2 panel a). M-shape peaks can occur at different seasons and at different geomagnetic background. For example, it was observed in the diurnal TEC variation during: (a) 20-21.04.2016 (Dstmin $=-10 \mathrm{nT}$, quiet conditions); (b) 30-31.10.2016 (Dstmin $=-41 \mathrm{nT}$, at the recovery phase of the moderate storm on 29.10.2016); and (d) 2021.12.2015 (Dstmin $=-148 \mathrm{nT}$, strong storm).

To sum up, the TEC night-time enhancements are the persistent trend in the diurnal TEC course over Mexico. Their probability is high in this region. Its intensity and maximum hour vary. No clear dependence of the night TEC enhancements on geomagnetic activity was revealed. There is a certain probability of occurrence of M-shape peak in the diurnal TEC maximum.

\subsection{Features of TEC behaviour during positive distur-} bances

Many years critical frequencies foF 2 measured by ground-based ionosondes were used to study the disturbed ionospheric state. The main interest of researchers was focused on negative disturbances. With the advent of total electron content data, measured with the help of navigational satellites, the interest has shifted towards positive disturbances. Recently, much attention is paid to this issue, for example [David and Sojka 2010]. According to Cander and Ciraolo (2009), positive enhancements of TEC can cause significant difficulties in space system operations within the period of low solar activity. The peculiarity of the present study is an attempt not only to study and describe TEC behaviour during the positive ionospheric disturbances but also to explain which part of the ionosphere is responsible for the TEC change.

It is known that during the periods of severe and great disturbances $\delta$ TEC variations can reach hundreds of percents. For instance, the positive disturbance over Mexico station on October 29-30, 2003 continued 16 hours with maximal $\delta$ TEC variations from $200 \%$ to $475 \%$ (The information on this and further examples is pro- 


\begin{tabular}{|c|c|c|c|c|}
\hline & Event & Mexico & Puerto Rico & Eglin \\
\hline 1 & $\begin{array}{l}\text { October 29-30, } 2003 \\
(\text { Dstmin }=-383 \mathrm{nT})\end{array}$ & $+(200-475) \%$ & $+(170-300) \%$ & $+200 \%$ \\
\hline 2 & $\begin{array}{c}\text { October 1, } 2012 \\
(\text { Dstmin }=-119 \mathrm{nT})\end{array}$ & $+225 \% ;-20 \%$ & $+110 \% ;-31 \%$ & $+110 \% ;-30 \%$ \\
\hline 3 & $\begin{array}{c}\text { March 17, } 2013 \\
(\text { Dstmin }=-132 \mathrm{nT})\end{array}$ & $-20 \% ;+79 \%$ & $+46 \%$ & $+68 \%$ \\
\hline 4 & $\begin{array}{l}\text { February 19, } 2014 \\
(\text { Dstmin }=-166 \mathrm{nT})\end{array}$ & $+43 \%$ & $-32 \%,+50 \%$ & $+34 \% ;-35 \%$ \\
\hline 5 & $\begin{array}{c}(\text { Dstmin }=-124 \mathrm{nT}) \text { October } \\
7,2015\end{array}$ & $+60 \%$ & $-34 \% ; 22 \%$ & $+40 \% ;-39 \%$ \\
\hline 6 & $\begin{array}{c}\text { March 17, } 2015 \\
(\text { Dstmin }=-223 \mathrm{nT})\end{array}$ & $+27 \% ;-17 \%$ & $+58 \%$ & $-50 \%$ \\
\hline 7 & $\begin{array}{c}\text { June 23, } 2015 \\
(\text { Dstmin }=-204 \mathrm{nT})\end{array}$ & $+49 \% ;-61 \%$ & $-65 \%$ & $+53 \% ;-54 \%$ \\
\hline 8 & $\begin{array}{l}\text { January 22-23, } 2014 \\
(\text { Dstmin }=-20 \mathrm{nT})\end{array}$ & $+45 \%$ & $+49 \%$ & $+35 \%$ \\
\hline
\end{tabular}

Table 4. Maximal $\delta$ TEC variations.

vided in Table 4: the events are arranged in order of their appearance in the text). At the same time a positive phase in Puerto Rico continued 8 hours with maximal $\delta$ TEC variations of $300 \%$ and in Eglin only one separate burst of $200 \%$ variation was observed. However, such intense events are rare. Positive disturbances are more frequent when Dst $\sim-100 \mathrm{nT}$. The event of October 1, 2012 may serve as an example: maximal $\delta$ TEC represented $225 \%$ in Mexico and $110 \%$ both in Ruerto Rico and Eglin.

Within the period under analysis $(2011-2015)$ there were 13 cases of strong (Dst<-100 nT) and two cases of severe storms (Dst $<-200 \mathrm{nT}$ ). During 11 of these geomagnetic events TEC followed the pattern "positive phase followed by negative phase" with the positive phase being much stronger in five cases. For example, during the mentioned storm of October 1, 2012 (Dstmin $=-119$ $\mathrm{nT})$ deviation $\delta \mathrm{TEC}=+225 \%$ was followed by $\delta$ TEC $=$ $-20 \%$. There was only one case of negative phase followed by positive phase in Mexico that occurred on March 17, 2013 (Dstmin = -132 nT). Two cases of only positive phase were observed: $\delta$ TEC $=+43 \%$ on February 19, 2014 (Dstmin $=-166 \mathrm{nT}$ ) and $\delta$ TEC $=+60 \%$ on October 7, 2015 (Dstmin $=-124 \mathrm{nT}$ ). It is noteworthy that two severe storms on March 17, 2015 (Dstmin = -223 nT) and June 23, 2015 (Dstmin $=-204 \mathrm{nT}$ ) provoked less TEC deviation than other events: $\delta$ TEC $<|28| \%$ in the first case and $\delta$ TEC $=+49 \%$ followed by $\delta$ TEC $=-61 \%$ in the second case respectively. At the same time it is characteristic for the region that sometimes $\delta$ TEC reaches high positive values on the quiet geomagnetic background. For instance, during January 22-23, 2014 STEC reached $+45 \%$ twice while Dstmin $=-20 \mathrm{nT}$ and H-component varied within the limits of $30 \mathrm{nT}$.

In the present study two periods were chosen for the analysis of positive disturbances: during high solar activity and during low solar activity.

\subsubsection{TEC variations during the period of high solar} activity

Sojka et al. [2012] suggested that perhaps daytime large-scale TEC enhancements have the longitudinal dependence and that the North American continent is a favored longitude sector for the appearance of such effects. Sojka et al. [2012] tested this suggestion using data from Millstone Hill station (Table 1). We test it for lower latitudes in the context of the event of November 6-7, 2001. It was a period of high solar activity. F10.7 $\mathrm{cm}$ solar flux in November, 2001 varied within (165275) s.f.u. Dst-index reached the value of $-292 \mathrm{nT}$ on November 6th.

To estimate the ionosphere state in Mexican and nearby regions data from Vertical Ionospheric Sounding (VIS), TEC and satellite data were compared. The storm occurred on November 6, 2001 with SSC at 01:53 UT. Figure 8 shows TEC variations during this storm for four stations located within the approximate latitude interval $20-45^{\circ} \mathrm{N}$ and longitude interval $70-100^{\circ} \mathrm{W}$ (Table 1). Each panel illustrates TEC values during the days of observation (obs), median TEC values for this month (med) and Dst-index showing the development of geomagnetic disturbance (0.1Dst). Dst values were reduced by ten for illustrative purpose. Disturbance in Millstone Hill started three hours after SSC. The rapid decrease of TEC occurred during several hours starting from 13 UT. Puerto Rico is more low-latitude station in the considered longitude sector. Here, TEC increase started at $13 \mathrm{UT}$, reached its maximal values within the interval 17-21 UT and ended at 13 UT on 


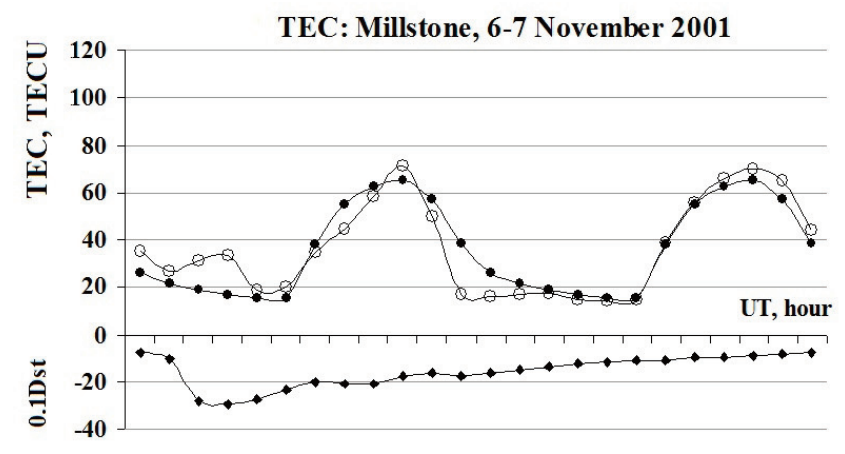

$\begin{array}{llllllllllll}1(6) & 5 & 9 & 13 & 17 & 21 & 1(7) & 5 & 9 & 13 & 17 & 21\end{array}$

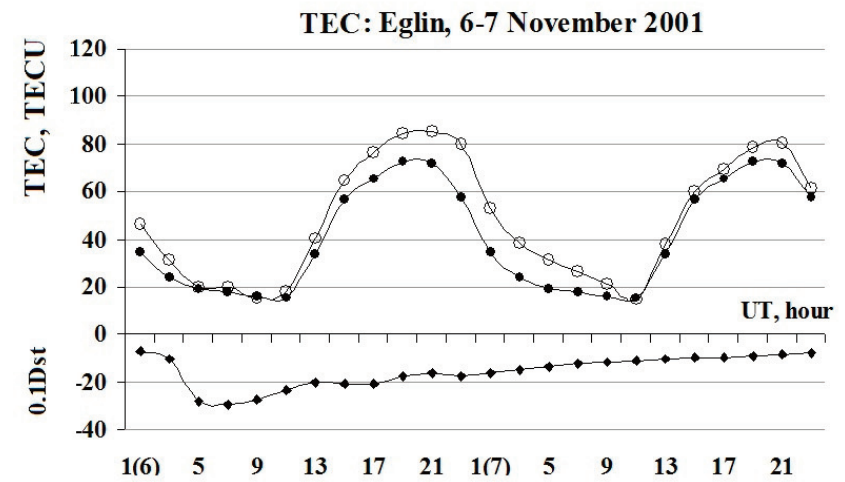

TEC: Puerto Rico, 6-7 November 2001

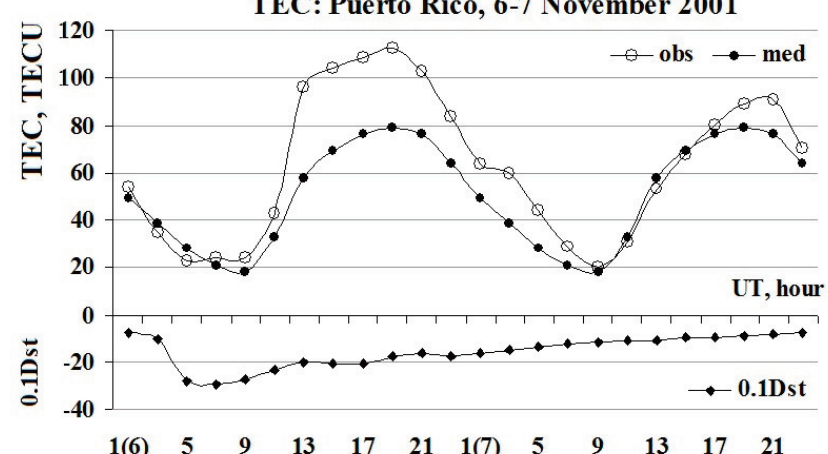

TEC: Mexico, 6-7 November 2001

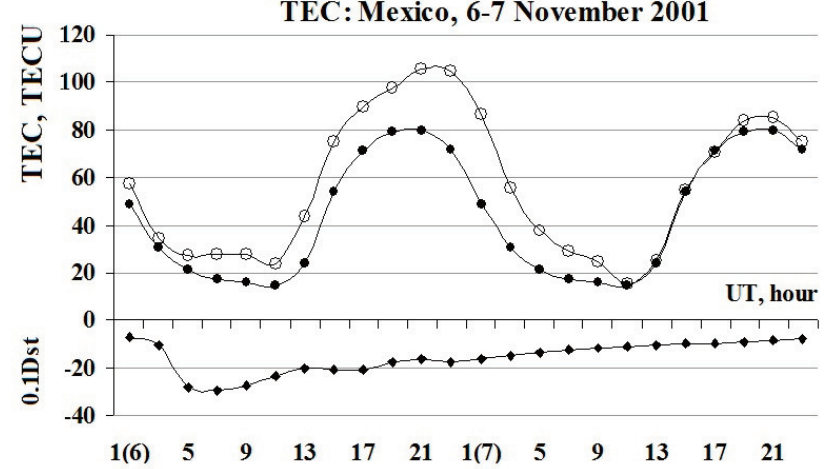

Figure 8. TEC and Dst-index variations for stations: Millstone Hill, Puerto Rico, Eglin and Mexico during the storm of Nobember 6-7, 2001. Curves for experimental values observed during the storm - (obs), curves for monthly median values - (med).

November 7, 2001. TEC behaviour over Eglin station was similar to Ruerto Rico but with lower values of TEC. Mexico had the longest period of positive disturbance with its maximum at 19-23 UT. VIS data for this period is avaliable for stations Millstone Hill and Eglin. The behaviour of critical frequency of F2-layer (foF2)

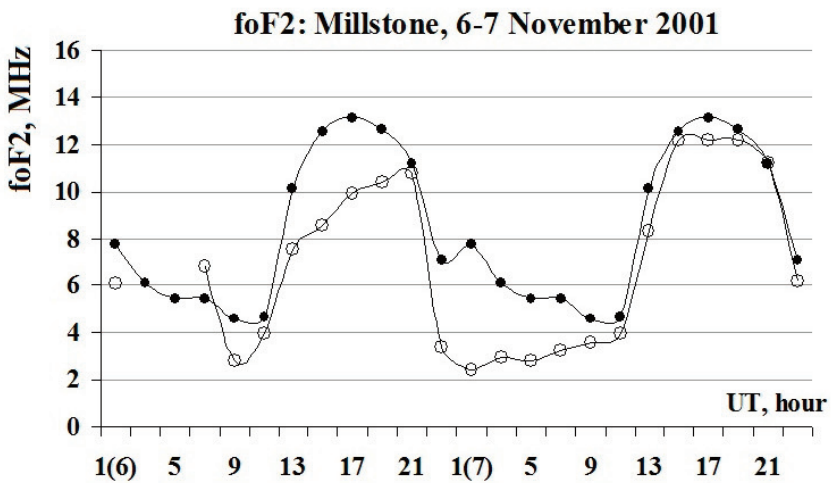

ionosphere response in more detail at these altitudes and to estimate how high the positive disturbance can be extended. Therefore, the regions responsible for TEC change can be qualitatively indicated.

The results of fne measurements by CHAMP and DMSP satellites during their passages over four con-

Figure 9. foF2 variations for stations Millstone Hill and Eglin during the storm of November 6-7, 2001. Curves for experimental values observed during the storm - (obs), curves for monthly median values - (med).

for two stations is shown in Figure 9. Certain dissimilarity in TEC and foF2 behaviour for both stations may indicate a different response on disturbance in topside and in bottom side ionosphere. The information about this can be obtained from data of plasma frequency (fne) from satellites. The fact that the satellites fly at different altitudes allows us to consider the sidered stations during the storm days are shown in Table 5. Day and time of satellite passage and its corresponding difference between observational and median fne values $\Delta$ fne $=$ fne(obs)- fne(med) are given . CHAMP and DMSP passed different number of times over each station that is why there are empty boxes in the table. 


\begin{tabular}{|c|c|c|c|c|c|c|c|c|c|c|c|c|}
\hline & \multicolumn{3}{|c|}{ Millstone } & \multicolumn{3}{|c|}{ Eglin } & \multicolumn{3}{|c|}{ Mexico } & \multicolumn{3}{|c|}{ Puerto Rico } \\
\hline & day & UT & $\begin{array}{l}\Delta \text { fne, } \\
\mathrm{MHz}\end{array}$ & day & UT & $\begin{array}{l}\Delta \text { fne, } \\
\mathrm{MHz}\end{array}$ & day & UT & $\begin{array}{l}\Delta \text { fne, } \\
M H z\end{array}$ & day & UT & $\begin{array}{l}\Delta \text { fne, } \\
M H z\end{array}$ \\
\hline \multirow{4}{*}{ 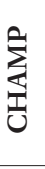 } & 6 & 0.1 & 2.76 & & & & 6 & 1.6 & 1.95 & & & \\
\hline & 6 & 11.5 & 1.23 & 6 & 13.1 & 2.34 & 6 & 13 & 4.5 & 6 & 11.5 & 5.01 \\
\hline & 6 & 23.5 & -2.89 & 7 & 0.9 & 2.66 & & & & 6 & 23.3 & 2.68 \\
\hline & & & & 7 & 12.3 & 0.62 & & & & & & \\
\hline \multirow{9}{*}{ 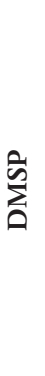 } & & & & 6 & 1.14 & 0.6 & 6 & 0.58 & 1.44 & & & \\
\hline & & & & 6 & 2.66 & 0.2 & 6 & 4.3 & 1.48 & & & \\
\hline & 6 & 11.33 & 0.86 & & & & 6 & 13.14 & 0.37 & 6 & 11.94 & 1.67 \\
\hline & 6 & 15.03 & 1.34 & 6 & 13.59 & 0.89 & 7 & 0.36 & 2.66 & 6 & 22.66 & 1.56 \\
\hline & 6 & 22.77 & -0.01 & 7 & 0.91 & 1.21 & 7 & 4.05 & 0.46 & & & \\
\hline & 7 & 11.1 & -0.36 & 7 & 13.36 & -0.2 & 7 & 12.9 & -0.55 & 7 & 11.21 & -0.36 \\
\hline & 7 & 13.3 & 0.1 & & & & 7 & 16.6 & 0.47 & & & \\
\hline & 7 & 14.79 & 0.64 & & & & & & & & & \\
\hline & 7 & 22.55 & 0.77 & & & & & & & 7 & 22.41 & 0.8 \\
\hline
\end{tabular}

Table 5. CHAMP and DMSP observation results.

CHAMP data showed a strong excess of fne(obs) over fne(med) for Millstone Hill near the midnight (UT) November $6^{\text {th }}$. The values of TEC(obs) also exceeded the values of TEC(med) at 01 UT November $6^{\text {th }}$ and 23 UT November $5^{\text {th }}$ (not shown). However, foF2(obs) was lower than foF2(med). This may prove that the increase of ionization occurred in the topside ionosphere. It was observed fne(obs) $>$ fne(med), TEC(obs) $>$ TEC(med) and foF 2 (obs) $\approx$ foF 2 (med) at 11.3 UT. During daytime only DMSP data was available at 15 UT. According to this data, fne(obs) > fne(med). Consequently, the bottomside ionosphere was responsible for TEC decrease here. The fne(obs) value was 1.5 times lower than fne(med) at 23.5 UT by CHAMP data. As the ionization by DMSP was near its median level, the main response was in topside part near the altitude hmF2.

The plasma frequencies by both satellites for Eglin at 13 UT are higher than their median values. When foF 2 (obs) $\approx$ foF2(med), the topside is responsible for TEC increase. This occurred around midnight of November 7th. At noon all the parameters were near their median values.

There are passages of both satellites over Mexico and Puerto Rico close in time. The positive disturbance was registered in all cases at the altitude of CHAMP satellite near hmF2 and at DMSP altitude in topside ionosphere, in contrast to higher latitudinal zone where the ionization variations can occur not simultaneously in the bottom and topside ionosphere.

It is necessary to consider the global picture of TEC behaviour at particular UT hours to understand if the Mexican region belongs to some particular zone. Figure 10 illustrates the global TEC distribution for geographic latitudes $20^{\circ} \mathrm{N}, 30^{\circ} \mathrm{N}$ and $45^{\circ} \mathrm{N}$ at the moments of the diurnal maximum of TEC within the interval 19-21 UT. Here, GIM JPL TEC data was used. Local hours with corresponding longitudes were laid off along the $\mathrm{X}$-axis. The plots of this figure were constructed this way in order to estimate whether TEC disturbance had the same or different sign along the mentioned latitudes and also whether some specific longitude sectors can be distinguished in regard to TEC behaviour. It is seen that the continuous positive TEC disturbance is present at the latitude of $20^{\circ} \mathrm{N}$ all around the globe (TECobs $>$ TECmed). This is the latitude of Mexico. The latitude of $30^{\circ} \mathrm{N}$ (latitude of Eglin) is characterized by the local transition to the quiet state (TECobs $\sim$ TECmed). The transition to negative disturbance and further negative plato (TECobs $<$ TECmed) is observed at $45^{\circ} \mathrm{N}$ (latitude of Milstone Hill) that will determine high latitudinal gradients. For estimation of these gradients the developed networks of local receivers are needed.

To sum up, it is shown that positive disturbances are characteristic for the Mexican longitudes. The intensity of disturbances can be higher than in the nearby regions. Both bottomside and topside ionosphere can be responsible for these disturbances.

\subsubsection{TEC variations during the period of low solar} activity

Cander and Ciraolo [2009] analyzed 15 cases of large short-lived storm-like disturbance TEC and foF2 enhancements between 2006 and 2007 for Chilton station (see coordinates in Table 1). Furthermore, the need for such a study at low-latitude regions was emphasized. We analyzed the same 15 events for Mexico station on base of GIM JPL. Geophysical conditions for chosen events are described in detail in [Cander and 
TEC, TECU: Lat $=20^{\circ}, 6$ November 2001

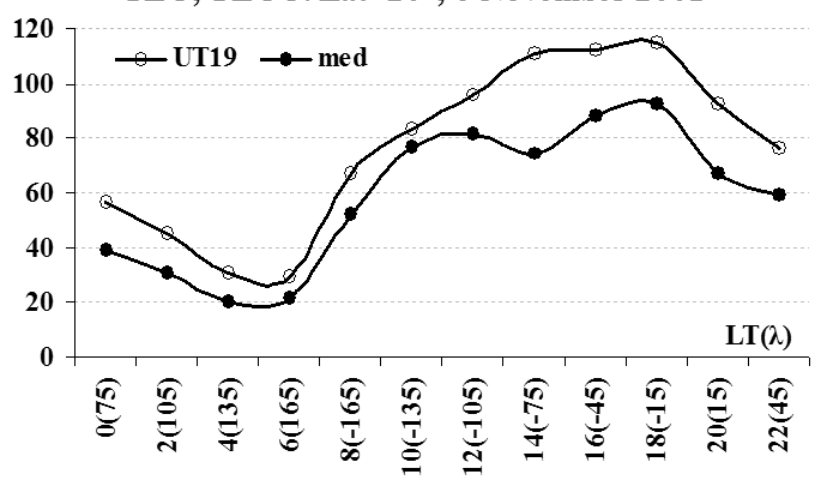

TEC, TECU: Lat $=30^{\circ}, 6$ November 2001

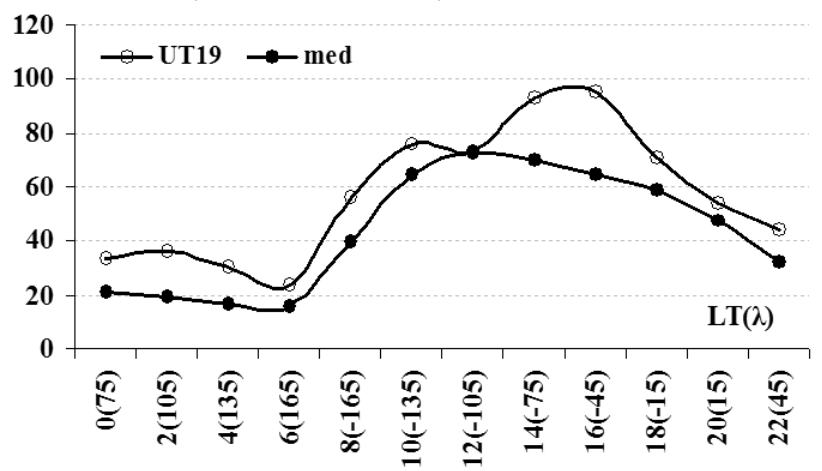

TEC, TECU: Lat $=45^{\circ}, 6$ November 2001

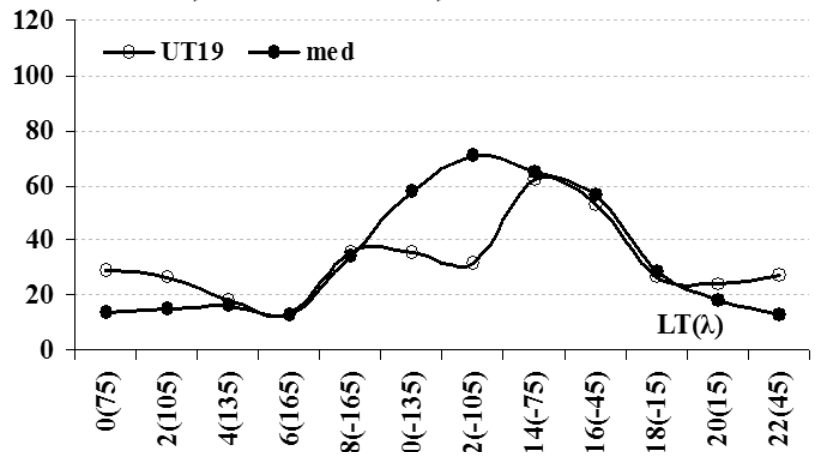

TEC, TECU: Lat $=20^{\circ}, 6$ November 2001

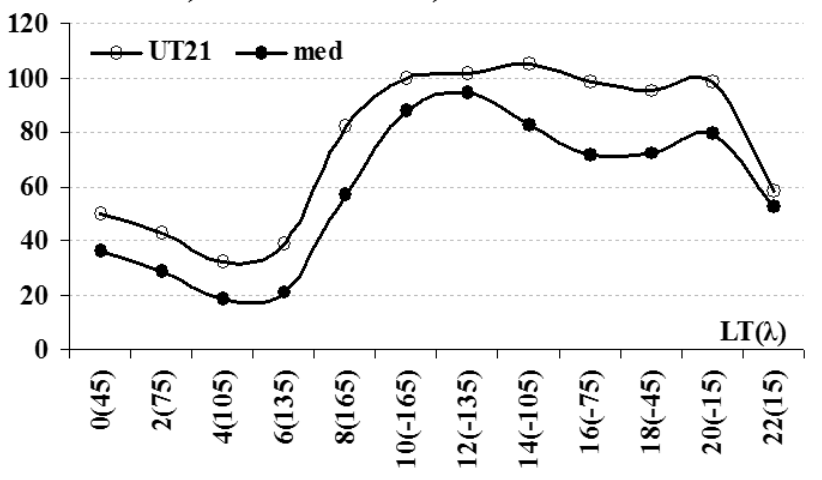

TEC, TECU: Lat $=30^{\circ}, 6$ November 2001

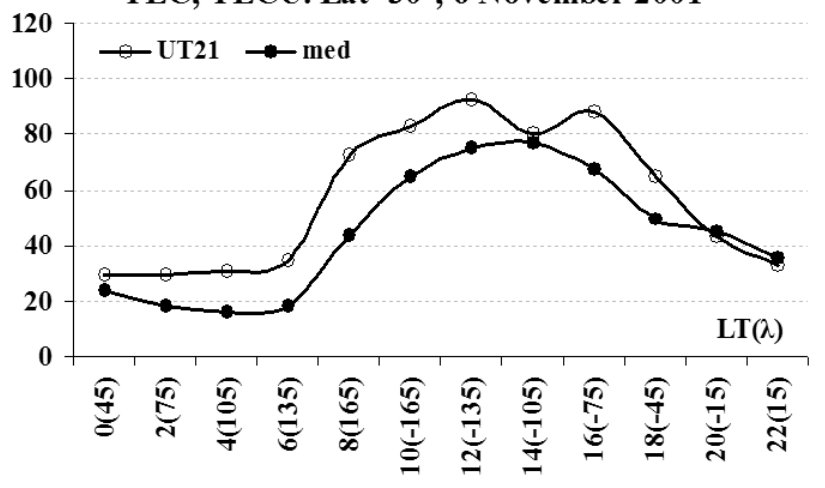

TEC, TECU: Lat $=45^{\circ}, 6$ November 2001

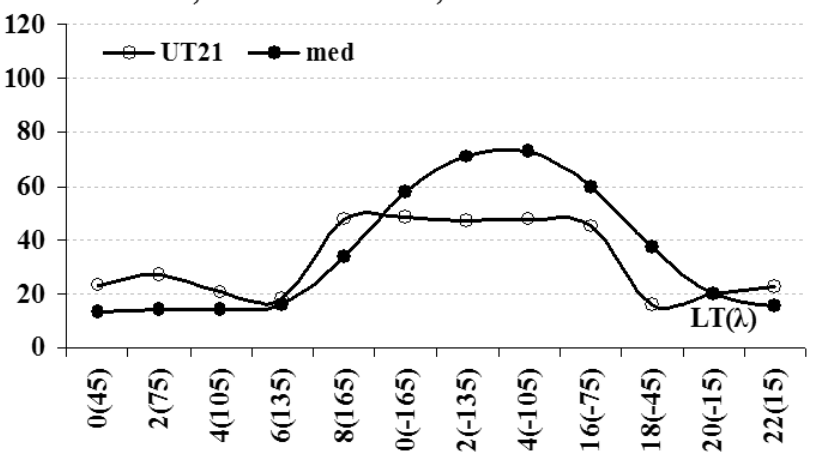

Figure 10. Global TEC distribution along the different geographic latitudes of Northern Hemisphere for November 6, 2001.

Ciraolo 2009]. Each period consists of three days including the enhancement. Maximum relative deviations of TEC ( $\delta$ TEC) were calculated on base of GIM JPL separately for day- and night-time for Chilton and Mexico stations for mentioned 15 events (Table 6). The results showed that positive enhancements were observed in all 15 cases at both stations during day-time. During night-time conditions, the enhancements were observed in 7 cases of 15 at Chilton and in 7 cases of 15 at Mexico (but simultaneously only in three cases). This means that the large short-lived storm-like enhancements are also characteristic for Mexico.

To illustrate this fact we consider two particular cases (marked with asterisk in Table 6): during November 19-21, 2007 (Dst = - 59 nT) and January 22-24, 2006 (quiet). The first event is characterized by the largest deviations. The second event was chosen because it belongs to the quietest geomagnetic period. Figure 11 shows TEC variations over Chilton and Mexico stations compared to their medians for both periods. It was interesting to estimate the spatial coverage of TEC enhancements that is, to answer the question how local this phenomenon can be. For this purpose, longitudinal dependences were calculated for latitudes $20^{\circ} \mathrm{N}$ and $50^{\circ} \mathrm{N}$ (approximate latitudes of two stations) similar to those in Figure 10. Figures 12 and 13 illustrate the results. It was found that the conditions were quiet at 12 UT of the prestorm day November $19^{\text {th }}, 2007$ along the latitude $50^{\circ} \mathrm{N}$. It also was quiet in general at $18 \mathrm{UT}$ at the latitude $20^{\circ} \mathrm{N}$ but with small TEC depletions over the longitudes between $180^{\circ}$ and $-60^{\circ}$. In contrast, at 12 UT of November $20^{\text {th }}, 2007$ the positive disturbance covered the zone of longitudes between $-45^{\circ}$ and $60^{\circ}$ (09-16 LT zone) along the latitude $50^{\circ} \mathrm{N}$. The maximal enhancement was ob- 


\begin{tabular}{|c|c|c|c|c|}
\hline date & $\begin{array}{c}\text { Max } \delta \text { TEC } \\
\text { day } \\
\text { Chilton }\end{array}$ & $\begin{array}{c}\text { Max } \delta T E C \\
\text { night } \\
\text { Chilton }\end{array}$ & $\begin{array}{c}\text { Max } \delta \text { TEC } \\
\text { day } \\
\text { Mexico }\end{array}$ & $\begin{array}{c}\text { Max } \delta \text { TEC } \\
\text { night } \\
\text { Mexico }\end{array}$ \\
\hline $16-18.04 .2007$ & 85.57 & - & 26.53 & 55.32 \\
\hline 27-29.04.2007 & 35.56 & - & 36.3 & - \\
\hline 06-08.05.2007 & 60 & - & 30.38 & 46.08 \\
\hline $21-23.05 .2007$ & 51.26 & - & 34.3 & - \\
\hline $13-15.07 .2007$ & 55.45 & 27.08 & 36.8 & 19.77 \\
\hline 19-21.07.2007 & 59.65 & & 16.4 & 22.08 \\
\hline $19-21.11 .2007^{\star}$ & 127.1 & 40.91 & 101.18 & - \\
\hline $22-24.01 .2006^{\star}$ & 92.78 & - & 36.7 & 29.52 \\
\hline $17-19.03 .2006$ & 55.37 & 25.26 & 79.9 & - \\
\hline 03-05.05.2006 & 71.13 & - & 35.7 & - \\
\hline $05-07.06 .2006$ & 52.49 & 42.54 & 55.67 & 52.47 \\
\hline $18-20.08 .2006$ & 81.82 & - & 82.4 & - \\
\hline $26-28.08 .2006$ & 81.13 & 18.52 & 80.63 & - \\
\hline $29.09-01.10 .2006$ & 84.82 & 38.64 & 24.44 & 22 \\
\hline $12-14.10 .2006$ & 61.34 & 47.27 & 48 & - \\
\hline
\end{tabular}

Table 6. TEC deviations for Mexico and Chilton stations during 15 storms.

TEC, TECU: Chilton, 19-21 November 2007

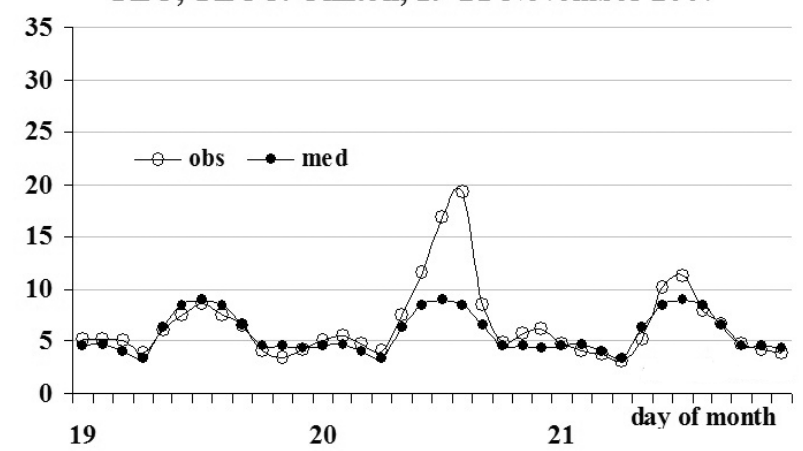

TEC, TECU: Chilton, 22-24 January 2006

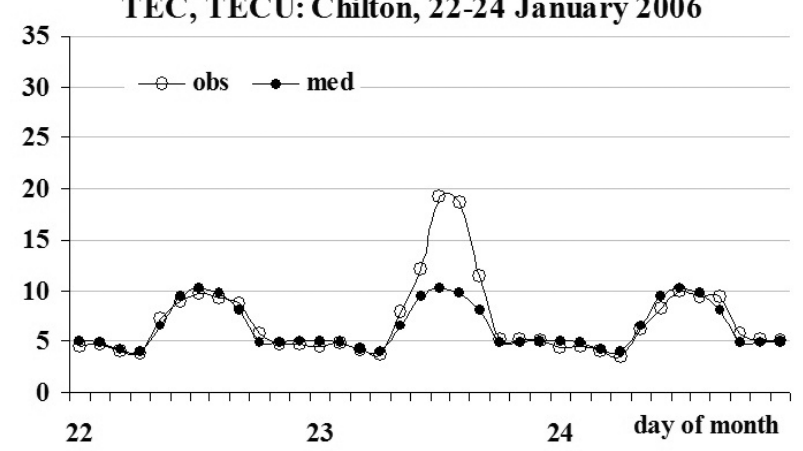

TEC, TECU: Mexico, 19-21 November 2007

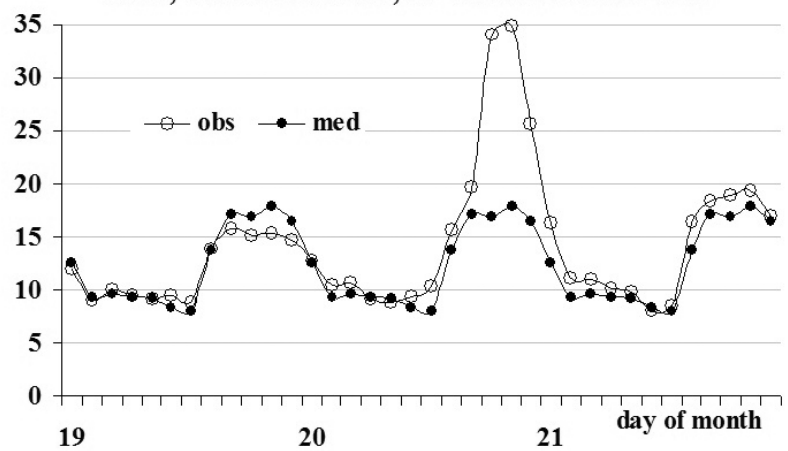

TEC, TECU: Mexico, 22-24 January 2006

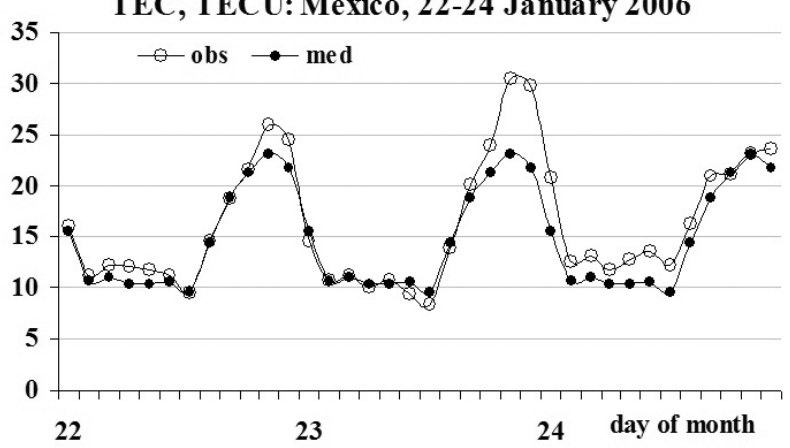

Figure 11. Illustration of short-lived TEC enhancements over Chilton and Mexico during November 19-21, 2007 (upper panels) and January 22-24, 2006 (lower panels).

served at Chilton longitude at 14 UT. At the latitude $20^{\circ} \mathrm{N}$ the positive disturbance was pronounced in a wide longitudinal zone between $-160^{\circ}$ and $60^{\circ}$ with its maximum being at $-90^{\circ}$ (longitude of Mexico). On the next day November 21st the ionosphere almost recovered to its quiet state with weak enhancements. At $20^{\circ} \mathrm{N}$ they were observed between longitudes $-165^{\circ}$ and $-30^{\circ}$ again covering all the territory of Mexico.
The global picture of TEC deviations on January 22-24, 2006 was similar: the maximal TEC enhancements along the latitude $20^{\circ} \mathrm{N}$ covered longitudes that include the Mexican region. The only difference is that in November 2007 the geomagnetic disturbance occurred and January 2006 was a quiet period. The last may indicate that the cause of the day-time TEC enhancements can be not related to geomagnetic disturbance. 


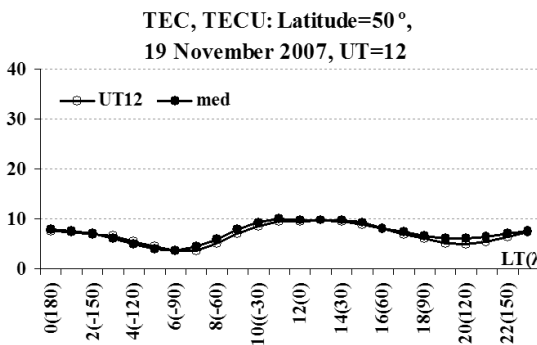

TEC, TECU: Latitude $=20^{\circ}$,

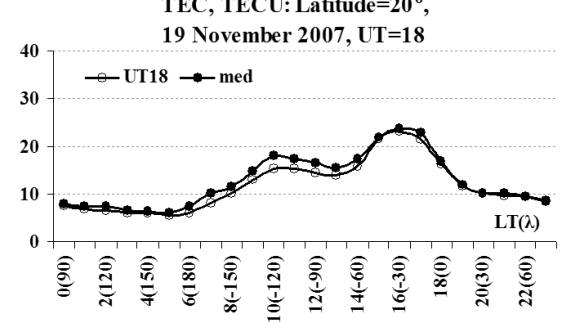

TEC, TECU: Latitude $=\mathbf{5 0}{ }^{\circ}$,

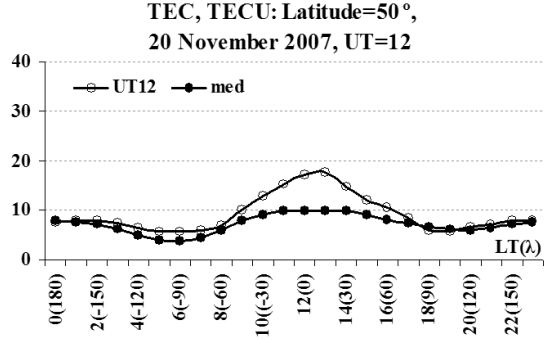

TEC, TECU: Latitude $=\mathbf{2 0}$,

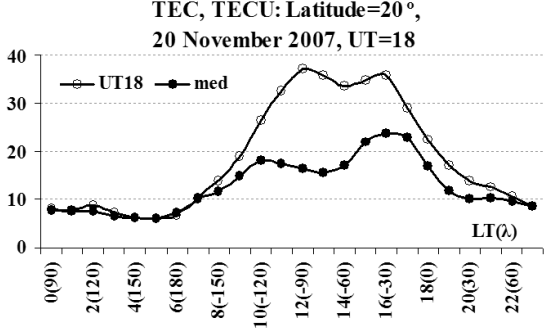

TEC, TECU: Latitude $=\mathbf{5 0}$,

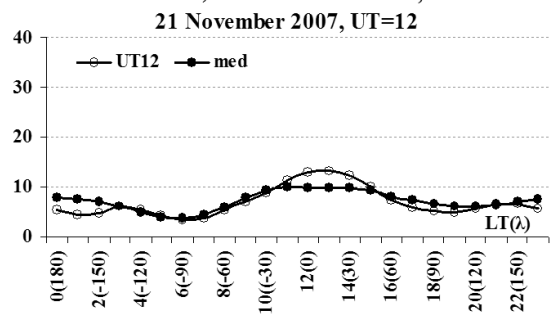

TEC, TECU: Latitude $=20^{\circ}$, 21 November 2007 , UT $=18$

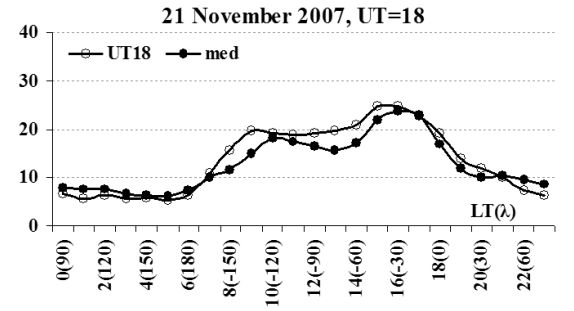

Figure 12. The same as for the Figure 10, but for November 19-21, 2007.

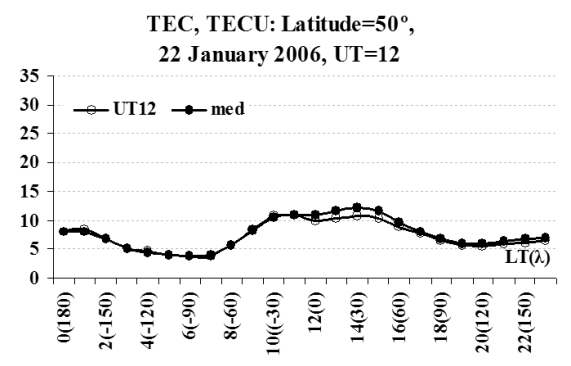

TEC, TECU: Latitude $=20^{\circ}$,

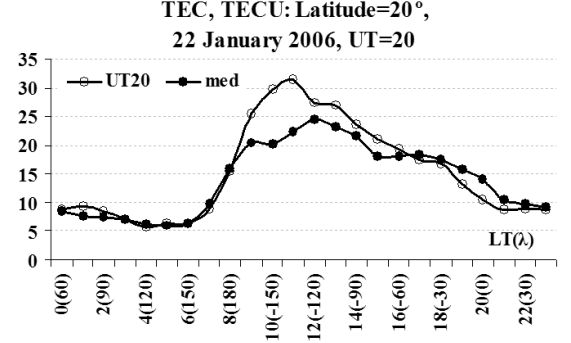

TEC, TECU: Latitude $=\mathbf{5 0} 0^{\circ}$,

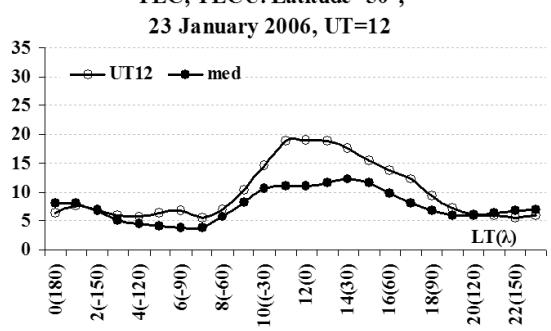

TEC, TECU: Latitude $=20^{\circ}$,

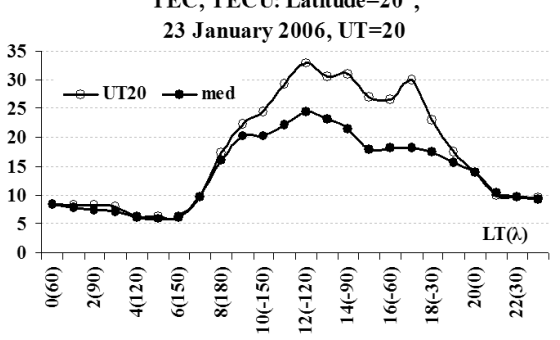

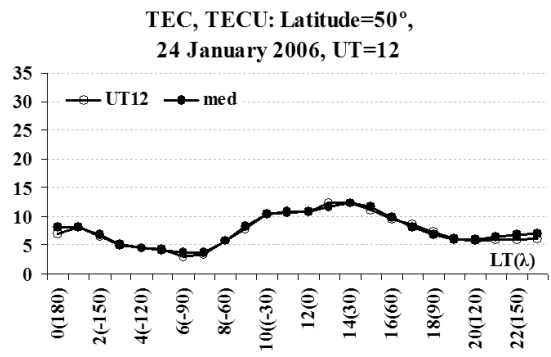

TEC, TECU: Latitude $=20^{\circ}$, 24 January 2006, UT=20

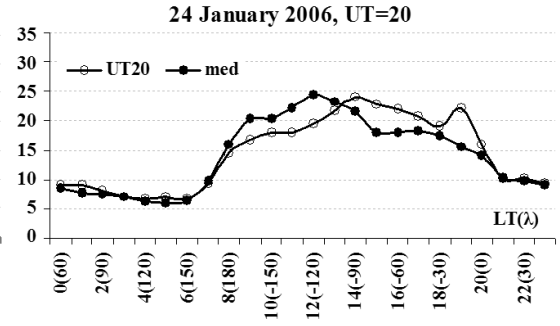

Figure 13. The same as for the Figure 10, but for January 22-24, 2006.

Thus, the analysis of longitudinal dependences showed that the zone of positive TEC deviations is rather wide but has its maximal values over the region that includes Mexico. This is another proof that short-lived TEC enhancements are characteristic for Mexico.

Table 7 shows data by CHAMP satellite during the days of maximal TEC values. Data by DMSP satellite was unavailable for this period. There were two times more passages over the Chilton station than over Mexico. The table does not list some results for night and morning hours to avoid empty boxes. This table is similar to Table 5. There is a clear confirmation of the positive character of disturbance for all the daytime passages. Recall that January 2006 was a quiet period.

To sum up, the examples considered in Section 3.5 prove the diversity of SW effects. Global disturbances affect Mexican region as expected. The peculiarity is in the intensity of the ionospheric response. The latitudinal zone to which Mexico belongs can be characterized by large gradients. This fact determines the need of continuous TEC monitoring based on data of the local receiver networks as well as the local monitoring of other ionospheric parameters. The positive short-lived TEC enhancements are characteristic for the considered region in the presence of weak and moderate geomagnetic disturbances and also under quiet conditions. The complex analysis of data from VIS, TEC and satellites showed that the bottom-side ionosphere response on the disturbance in this region is different to the response at higher latitudes. 


\begin{tabular}{cccccc}
\hline \multicolumn{3}{c}{ Chilton } & \multicolumn{5}{c}{ Mexico } \\
\hline day & UT & $\begin{array}{c}\Delta \text { fne, } \\
\text { MHz }\end{array}$ & day & UT & $\begin{array}{c}\Delta \text { fne, } \\
\text { MHz }\end{array}$ \\
\hline 17.04 .2007 & $12: 44$ & 0.22 & 07.05 .2007 & $21: 32$ & 0.24 \\
20.11 .2007 & $8: 27$ & 0.45 & 22.05 .2007 & $19: 49$ & 0.34 \\
23.01 .2006 & $9: 52$ & 0.61 & 14.07 .2007 & $3: 08$ & 0.33 \\
& & & & & \\
06.06 .2006 & $21: 45$ & 0.56 & 20.07 .2007 & $2: 22$ & -0.69 \\
19.08 .2006 & $14: 25$ & 2.01 & 18.03 .2006 & $11: 00$ & 0.33 \\
27.08 .2006 & $13: 27$ & 1.81 & 04.05 .2006 & $19: 37$ & 2.63 \\
30.09 .2006 & $10: 22$ & 0.97 & 27.08 .2006 & $8: 25$ & 0.27 \\
13.10 .2006 & $21: 55$ & 0.83 & 13.10 .2006 & $16: 16$ & 0.81 \\
\hline
\end{tabular}

Table 7. CHAMP observation results.

\section{Conclusions}

In the present work we study the regular and disturbed behaviour of ionospheric TEC for the understudied Mexican region. We obtain TEC from data of: 1) local GNSS receiver networks using the new calculation method TayAbsTEC; and 2) the global network of GNSS receivers using GIM technology. Our analysis reveals the following.

1) Benefits and limitations of both sources of data in Mexican region.

GIM limitations for continuous ionospheric monitoring are: (a) availability of IONEX-files with minimum three-day delay and with low time-resolution (one or two hours); (b) lack of Mexican receivers (only one) included in the IGS ground network and as a consequence important role of interpolation in GIM for Mexico. TEC extracted from RINEX-files of local receivers with TayAbsTEC provides higher temporal resolution (up to three minutes) and can be used for quasi-real time monitoring of the ionosphere. The last is vital for the end users of ionospheric information like the services of aerodromes, telecommunications, etc. At the same time, GIM data can be used when there is a gap of local data or for the analysis during previous decades. GIM TEC frequently manifests less intensity of ionospheric response on SW events. The more intense the disturbance, the more pronounced the difference in TEC by two methods.

2) Diurnal, seasonal, annual and over solar cycle variations of TEC over Mexico.

(a) TEC increases with the growth of solar activity and decreases with its decrease.

(b) Two annual TEC "minima" and two "maxima" are consistent with an "annual anomaly". The periods of lowest and highest TEC are slightly shifted from the solar solstice and equinoctial months. This shift is not stable and depends on the year. In general, TEC values are highest in April and October and lowest during DecemberJanuary and July.

(c) The main diurnal TEC maximum is observed near 14 LT (20 UT) throughout Mexico during all four seasons.

(d) Night-time TEC enhancement as the second diurnal maximum is observed with high probability. Its onset time varies within the local night hours. The occurrence of night-time enhancement does not appear to depend on geomagnetic activity level.

(e) Five years of data (2011-2015) suggest that the winter and summer TEC values are comparable. This means the "winter anomaly" presence.

TEC in Mexico was compared to TEC of other mid-low-latitude zones: South East Zone and neighboring to Mexico regions. The similarities include the shift of the main diurnal maximum to $14 \mathrm{LT}$, presence of annual anomaly, dependence on solar activity. The differences include the winter anomaly presence and the high probability of night-time TEC enhancements.

3) Positive disturbances as the specific feature of TEC behaviour.

Our study reveals an important TEC variation in the Mexican region: the occurrence of short-lived TEC enhancements. These are observed both during high and low solar activity. The amplitude of such enhancements is 3-4 times higher than the expected value and $1.5-2$ times higher than in the neighboring regions. Such TEC bursts occur not just in the bottom-side but also in the topside ionosphere and can have a significant impact on operation of satellite communication systems, groundbased and satellite radars. The last circumstance is constantly confirmed by measurements of Mexican Array Radio Telescope operating at $140 \mathrm{MHz}$ and detecting radio signal anomalies during ionospheric disturbances [Carillo-Vargas et al. 2016]. The reasons for these bursts of even quiet-time enhanced electron density have not been identified yet. The only way of detecting these bursts is via continuous monitoring of TEC with use of local networks of GNSS receivers.

Acknowledgements. SCiESMEX is partially funded by CONACyT-AEM Grant 2014- 01-247722, CONACyT LN 269195, and DGAPA-PAPIIT Grant IN106916. The work of Maltseva O.A. was supported by grant under the state task N3.9696.2017 / 8.9 from Ministry of Education and Science of Russia. The authors express 
their gratitude to the services of IGS for the opportunity of using IONEX data via Internet and to SPIDR database http://spidr.ngdc.noaa.gov/spidr/ for the ionosonde data. The OMNI data were obtained from the GSFC/SPDF OMNIWeb interface at http: / / omniweb.gsfc.nasa.gov. GPS Rinex data were obtained from the following GPS permanent networks: the Mexican Servicio Sismológico Nacional (SSN), IGEF-UNAM, SSN-TLALOCNet and TLALOCNet. We thank their personnel, in particular, the SSN personnel and Jose A. Santiago for station maintenance, data acquisition and distribution, from SSN, SSN-TLALOCNet and IGEF-UNAM networks respectively. We also gratefully acknowledge field operations, engineering and IT support for the TLALOCNet and SSN-TLALOCNet GPS-Met networks from Luis Salazar-Tlaczani (Instituto de Geofisica-UNAM), John Galetzka, Adam Woolace and the whole engineering staff at UNAVCO Inc. We thank the UNAVCO service (www.unavco.org) for the opportunity of downloading data via Internet. Portions of the TLALOCNet and SSN-TLALOCNet GPS network operations were supported by the National Science Foundation under award EAR1338091 to UNAVCO Inc., CONACyT projects 253760 and 256012, UNAM-PAPIIT project IN109315-3 to E. Cabral-Cano and UNAMPAPIIT project IN111509 to R-Pérez. SSN GPS stations field, IT operations and maintenance were supported by the SSN. We thank the LACIGE-UNAM at ENES unidad Morelia for the data provided by GPS receiver, acquired through infrastructure CONACyT grant: 253691. The authors express their gratitude to Ilya Zhivetiev from the Institute of Cosmophysical Research and Radio Wave Propagation FEB RAS for providing "tec-suite" software and Yury Yasyukevich and Anna Mylnikova from the Institute of Solar-Terrestrial Physics SB RAS for providing "TayAbsTEC" software for this study (http://www.gnss-lab.org). The authors would like to thank Gerardo Cifuentes, Esteban Hernández, and Ana Caccavari for providing the magnetic field data from Teoloyucan Geomagnetic Observatory. The authors thank Dr. Francisco Azpilicueta for his comments on this work. The authors would like to thank the Editors and the anonymous reviewers for their contributing comments.

\section{References}

Afraimovich, E.L. and N.P. Perevalova (2006). GPSmonitoring of Earth upper atmosphere, Irkutsk, Russian Academy of Sciences, Siberian Branch, 460p., ISBN 5-98277-033-7.

Arikan, F., C.B. Erol and O. Arikan (2003). Regularized estimation of vertical total electron content from Global Positioning System data, J. Geophys. Res., 108, A12, 1469, doi:10.1029/2002JA009605.

Azpilicueta, F., C. Brunini and S.M. Radicella (2012). Semi-annual Anomaly and Annual Asymmetry on TOPEX TEC During a Full Solar Cycle, In: Kenyon S., Pacino M., Marti U. (eds) Geodesy for Planet Earth. International Association of Geodesy Symposia, 136, 769-774, Springer, Berlin, Heidelberg, doi: 10.1007/978-3-642-20338-1_96.

Beutler, G., M. Rothacher, S. Schaer and R.E. Neilan (1999). The International GPS Service (IGS): An Interdisciplinary Service in Support of Earth Sciences, Advances in Space Research 23(4), 631-653, doi: 10.1016/S0273-1177(99)00160-X.

Bilitza, D., D. Altadill, Y.Zhang, C. Mertens, V. Truhlik, P. Richards, L.-A. McKinnell and B. Reinisch (2014). The International Reference Ionosphere 2012 - a model of international collaboration, J. Space Weather Space Clim., 4(A07), 1-12, doi:10.1051/swsc/ 2014004.

Blagoveshchensky, D.V. (2011). Space weather and ionospheric waves, Saarbrücken, Germany, LAP PALMARIUM Academic Publishing GmbH\&Co, KG, 123p, ISBN: 978-3-8473-9290-3.

Cander, L.R. and L. Ciraolo (2009). Ionospheric Total Electron Content and Critical Frequencies over Europe at Solar Minimum, Acta Geophysica, 58(3), 468-490, doi: 10.2478/s11600-009-0061-2.

Carrillo-Vargas, A., R. Pérez-Enríquez, M. RodríguezMartínez, R. Lopez-Montes, G.A. Casillas-Pérez and E.A. Araujo-Pradere (2011). Ionospheric disturbances detected by MEXART, Advances in Space Research, doi: 10.1016/j.asr.2011.12.017.

Carrillo-Vargas, A., R. Pérez-Enríquez, R. LopezMontes, M. Rodríguez-Martínez and L.G. UgaldeCalvillo (2016). Radio signal anomalies detected with MEXART in 2012 during the recovery phase of geomagnetic storms, Advances in Space Research, doi: $10.1016 / \mathrm{j}$.asr.2016.05.014

Çepni, M.S., L.V. Potts and J.B. Miima (2013). High-resolution station-based diurnal ionospheric total electron content (TEC) from dual-frequency GPS observations, Space Weather, 11, 520-528.

Cipagauta-Lara, E.C. and H.J. Durand-Manterola (2010). Effect of geomagnetic storms on the ionosphere of the El Cerrillo (Toluca, Mexico) y Boulder (Colorado, USA) stations, Revista mexicana de ciencias geologicas, 27(2), 366-373.

David, M. and J.J. Sojka (2010). Single-day dayside density enhancements over Europe: A survey of a halfcentury of ionosonde data, Journal of Geophysical Research, 115, A12311, doi: 10.1029/2010JA015711.

Gonzalez-Esparza, J.A., V. De la Luz, P. CoronaRomero, J.C. Mejia-Ambriz, L.X. Gonzalez, M.A. Sergeeva, E. Romero-Hernandez and E. Aguilar-Rodriguez (2017). Mexican Space Weather Service (SCIESMEX), Space Weather, 15, 1-9, doi: 10.1002/ 2016SW001496.

Gulyaeva, T.L., F. Arikan, M. Hernandez-Pajares and I. Stanislawska (2013). GIM-TEC adaptive ionospheric 
weather assessment and forecast system, J. Atmosph. Solar-Terr. Phys., 102, 329-340, doi: 10.1016/j.jastp.2013.06.011.

Hernandez-Pajares, M., J.M. Juan and J. Sanz (1997). High-resolution TEC monitoring method using permanent ground GPS receivers, Geophys. Res. Lett., 24, 1643-1646.

Hernandez-Pajares, M., Juan J.M., Orus R., Garcia-Rigo A., Feltens J., Komjathy A., Schaer S.C. and Krankowski A. (2009). The IGS VTEC maps: a reliable source of ionospheric information since 1998, J. Geod., 83, 263-275.

Ho, C.M., A.J. Mannucci, U.J. Lindqwister, X. Pi, B.T. Tsurutani, L. Sparks, B.A. Iijima, B.D. Wilson, I. Harris and M.J. Reyes (1998). Global ionospheric TEC variations during January 10, 1997 storm, Geophysical Research Letters, 25(15), 2589-2592, doi: 10.1029/98GL00539.

Jakowski, N., E. Sardon, E. Engler, A. Jungstand and D. Klahn (1996). Relationships between GPS-signal propagation errors and EISCAT observations, Ann. Geophys., 14, pp.1429-1436,

Kutiev I., Y. Otsuka, A. Saito and S. Watanabe (2006). GPS observations of post-storm TEC enhancements at low latitudes, Earth Planets Space, 58(11), 1479-1486.

Lopez-Montes, R., R. Perez-Enriquez and E.A. AraujoPradere (2012). The impact of large solar events on the total electron content of the ionosphere at mid latitudes, Advances in Space Research, 49, 1167 1179, doi: 10.1016/j.asr.2012.01.008.

Lopez-Montes, R., R. Perez-Enriquez, E.A. AraujoPradere and J.A.L. Cruz-Abeyro (2015). Fractal and wavelet analysis evaluation of the mid latitude ionospheric disturbances associated with major geomagnetic storms, Advances in Space Research, 55(2), 586-596, doi: 10.1016/j.asr.2014.10.037.

Liu, R.-Y., Y.-W. Wu and B.-C. Zhang (2014). Comparisons of the Variation of the Ionospheric TEC with NmF2 over China, Proceedings XXXI General Assembly and Scientific Symposium of URSIGAS2014, paper 1333, 1-4.

Maltseva, O.A., N.S. Mozhaeva, O.S. Poltavsky and G.A. Zhbankov (2012). Use of TEC global maps and the IRI model to study ionospheric response to geomagnetic disturbances, Adv. Space Res., 49, 1076-1087, doi: $10.1016 /$ j.asr.2012.01.005

Mannucci, A.J., B.D. Wilson, D.N. Yuan, C.H. Ho, U.J. Lindqwister and T.F. Runge (1998). A global mapping technique for GPS-derived ionospheric total electron content measurements, Radio Science, 33(3), 565582.
Mylnikova, A.A. and Yu.V. Yasyukevich (2016). Validation of the Technique for Estimation of Absolute Total Electron Content and its Gradients, Proceedings of $\mathrm{V}$ International conference Atmosphere, Ionosphere, Safety, Kaliningrad, Russia, 174-179, ISBN 978-5-9971-0412-2.

Perna, L., M. Pezzopane, E. Zuccheretti, P.R. Fagundes, R. de Jesus, M.A. Cabrera and R.G. Ezquer (2014). Unusual nighttime impulsive foF2 enhancements at low latitudes: Phenomenology and possible explanations, Adv. Space Res., 54, 363-384.

Rodríguez-Martínez, M., H.R. Pérez-Enríquez, A. Carrillo-Vargas, R. López-Montes, E.A. Araujo-Pradere, G.A. Casillas-Pérez and J.A.L. Cruz-Abeyro (2014). Ionospheric Disturbances and Their Impact on IPS Using MEXART Observations, Solar Phys., 289, 2677-2695, doi 10.1007/s11207-014-0496-8.

Sardon, E., A. Rius and N. Zarraoa (1994). Estimation of the receiver differential biases and the ionospheric total electron content from Global Positioning System observations, Radio Sci., 29, 577-586.

Schaer, S., G. Beutler, L. Mervart, M. Rothacher and U. Wild (1995). Global and regional ionosphere models using the GPS double difference phase observable, IGS Workshop, Potsdam, Germany, May 15-17, 1-16.

Schaer, S., G. Beutler and M. Rothacher (1998). Mapping and predicting the ionosphere, Proc. IGS AC Workshop, Darmstadt, Germany, February 9-11, 307-320.

Sojka, J.J., M. David, R.W. Schunk and R.A. Heelis (2012). A modeling study of the longitudinal dependence of storm time midlatitude dayside total electron content enhancements, J. Geophys. Res., 117, A02315, doi:10.1029/2011JA017000.

Takahashi, H., C.M. Wrasse, C.M. Denardini, M.B. Padua, E.R. de Paula, S.M.A. Costa, Y. Otsuka, K. Shiokawa, J.F. Galera Monico, A. Ivo and N. Sant'Anna (2016). Ionospheric TEC Weather Map Over South America, Space Weather, 14, 937-949, doi: 10.1002/2016SW001474.

Unnikrishnan, K., R. Balachandran Nair and C. Venugopal (2002). A comparative study of night-time enhancement of TEC at a low latitude station on storm and quiet nights including the local time, season and solar activity dependence, Annales Geophysicae, 20, 1843-1850.

Wang, X., H. Fang, J. Niu and S. Wang (2016). Statistics on the critical frequency of ionospheric sporadic $\mathrm{E}$ layer observed at Puerto Rico region (in Chinese), Chin. J. Space Sci., 36(1), 18-24, doi: 10.11728/cjss2016.01.018.

Yakovets, A.F., V.V. Vodyannikov, G.I. Gordienko and Yu.G. Litvinov (2014). Some features of nighttime 
enhancements in the electron concentration in the F2-layer maximum of the midlatitude ionosphere, Geomagnetism and Aeronomy, 54(6), $791-801$.

Yasyukevich, Yu.V., A.A. Mylnikova, V.E. Kunitsyn and A.M. Padokhin (2015a). Influence of GPS / GLONASS Differential Code Biases on the Determination Accuracy of the Absolute Total Electron Content in the Ionosphere, Geomagnetism and Aeronomy, 55(60, 763-769, ISSN 0016_7932.

Yasyukevich, Yu., A.A. Mylnikova and A.S. Polyakova (2015b). Estimating the total electron content absolute value from the GPS / GLONASS data, Results in Physics, 5, 32-33, doi: 10.1016/j.rinp.2014.12.006.

Yu, Y., W. Wan, B. Xiong, Z. Ren, B. Zhao, Y. Zhang, B. Ning and L. Liu (2015). Modeling Chinese ionospheric layer parameters based on EOF analysis, Space Weather, 13, 339-355, doi: 10.1002/2014SW001159.

\footnotetext{
${ }^{\star}$ Corresponding author: Maria Sergeeva,

Instituto de Geofisica, Unidad Michoacan, Universidad Nacional Autonoma de Mexico, Morelia, Mexico;

email: maria.a.sergeeva@gmail.com, sergeeva@geofisica.unam.mx

(C) 2018 by the Istituto Nazionale di Geofisica e Vulcanologia. All rights reserved.
} 